Article

\title{
Seismic and Energy Integrated Retrofitting of Existing Buildings with an Innovative ICF-Based System: Design Principles and Case Studies
}

\author{
Valentina Pertile ${ }^{1}$, Alberto Stella ${ }^{2} \mathbb{D}$, Lorenzo De Stefani ${ }^{1}$ and Roberto Scotta ${ }^{1, *}$ \\ 1 Dipartimento di Ingegneria Civile, Edile e Ambientale, Università degli Studi di Padova, Via Marzolo 9, \\ 35131 Padova, Italy; valentina.pertile@dicea.unipd.it (V.P.); lorenzo.destefani@dicea.unipd.it (L.D.S.) \\ 2 Dipartimento di Culture del Progetto, Università IUAV di Venezia, Dorsoduro 2206, 30123 Venezia, Italy; \\ astella@iuav.it \\ * Correspondence: roberto.scotta@unipd.it
}

check for updates

Citation: Pertile, V.; Stella, A.; De Stefani, L.; Scotta, R. Seismic and Energy Integrated Retrofitting of Existing Buildings with an Innovative ICF-Based System: Design Principles and Case Studies. Sustainability 2021, 13, 9363. https://doi.org/10.3390/ su13169363

Academic Editors: Maria Rosa Valluzzi and Angelo Masi

Received: 30 June 2021

Accepted: 31 July 2021

Published: 20 August 2021

Publisher's Note: MDPI stays neutral with regard to jurisdictional claims in published maps and institutional affiliations.

Copyright: (c) 2021 by the authors. Licensee MDPI, Basel, Switzerland. This article is an open access article distributed under the terms and conditions of the Creative Commons Attribution (CC BY) license (https:/ / creativecommons.org/licenses/by/ $4.0 /)$.

\begin{abstract}
This work proposes an innovative integrated retrofitting system aiming to improve both the seismic and energy performance of existing reinforced concrete and masonry buildings. The system is based on engineered insulating concrete form panels, installed on the outside of existing buildings as a shell exoskeleton. A key major advantage of the proposed system is that it addresses the contemporary improvement of seismic and energy performances of existing buildings in a single installation stage, operating exclusively from outside of the building. The insulating formworks are ad hoc prefabricated in a factory on the base of the specific geometry of the existing buildings so as to greatly maximize the ratio between overall retrofitting benefits and costs and at the same time to simplify the installation procedures. The objectives of the presented research are, on one hand, to highlight the major structural issues that the system aims to address, and on the other hand to illustrate the main characteristics and combined benefits of the proposed retrofitting system. From a structural point of view, the proposed system is conceived to behave as a non-dissipative structure with regard to seismic actions, and the lateral strength and stiffness of the structural elements are designed accordingly. An analytical design approach is proposed and validated using the available data from an experimental test performed on a full-scale simple building. Moreover, numerical modeling strategies for the proposed system are illustrated for two complex case study buildings. The results of the analyses show a considerable increase in lateral stiffness of the retrofitted buildings that, considering the non-dissipative behavior of the elements, leads to a relevant reduction of seismic deformation demand on existing structural elements.
\end{abstract}

Keywords: integrated retrofit; ICF; thin reinforced concrete walls; existing buildings; case study

\section{Motivation and Aims}

Many regions in the world that have a high level of anthropization are also characterized by a high seismic hazard. Focusing on the European region, the seismicity is not evenly distributed among nations and a different evolution of seismic design codes occurred in each country [1]. Moreover, most of the building stock in Europe was built before 1980, when many of the adopted design codes still contained inadequate or limited provisions for the seismic design of structures. As a consequence, there are today a considerable number of existing buildings characterized by a high seismic vulnerability. In many cases, these buildings also have a low energy efficiency, which produces high management costs and high greenhouse gasses emissions in the atmosphere. In order to address such a combination of issues, several possible solutions have been proposed, which include, for example, the demolition-and-reconstruction or the renovation of buildings.

The choice between these different solutions is influenced by many factors, involving technical, economic, and social aspects [2,3]. In this context, life cycle assessment (LCA) and 
life cycle cost (LCC) procedures can provide effective tools to support this decision $[4,5]$. Major benefits of renovation interventions include, among others, the fact that further consumption of resources and waste production is avoided. Moreover, the environmental total impact of the renovation process is lower compared to that of a demolition-reconstruction intervention [3].

Regarding the type of retrofit intervention, Calvi et al. [6] proposed a benefit-cost approach to assess the different results of improving earthquake resilience only, energy efficiency only, or both. Their work showed that the maximum benefit-cost ratio was obtained for integrated interventions. Integrated retrofit systems are technological solutions that can improve both energy efficiency and structural performance of buildings, allowing the extension of their residual life while maximizing benefits at the least cost. Belleri and Marini [7] pointed out that interventions that aim only at the energy consumption improvement of the building are not effective in reducing its embodied equivalent carbon dioxide if the contributions due to seismic risk are considered. Moreover, Pohoryles et al. [8] observed that energy efficiency intervention could be a useless cost if realized on seismically vulnerable buildings. In particular, their work presents the analysis of twenty case-study cities located in Europe with different levels of seismic hazard and climatic conditions. Several typical European building typologies with different thermal and seismic performances were then defined and analyzed for each case-study city. The combined seismic and energy performance of buildings was classified using the performance levels proposed by Calvi et al. [6] considering the sum of energy and seismic expected annual loss (EAL) as an index. The impact of the renovation strategy in terms of cost-benefits for each seismic zone was then evaluated by assessing the payback periods compared with the initial investment costs and the energy costs and seismic loss savings. The implementation of an increased renovation rate was shown to be economically efficient, highlighting the renovation strategies as more viable. In addition, in cases where seismic retrofitting is essential due to high seismic vulnerability, performing the combined retrofit at once instead of separate interventions showed a significant reduction in the intervention's payback period. Mastroberti et al. [9] also used an approach based on EAL estimation for evaluating the economic advantages of an integrated retrofitting approach. The study proved that global retrofit interventions that combine enhancement of both structural and energy performance are economically feasible and also more effective in terms of seismic performance of the buildings, compared to local interventions.

The aforementioned works highlight how the importance of holistic renovation $[10,11]$ and sustainable building renovation (SBR) [12] principles is becoming more and more recognized in recent years, leading to retrofitting approaches that involve several, or possibly all, building deficiencies. However, the employment of these approaches in current design practice still faces several obstacles. In particular, several technical, financial, and organizational issues prevent the extensive use of integrated retrofitting approaches [13]. However, in recent years, governments have been allocating important resources to promote renovation interventions on existing buildings aimed at improving their seismic and energy performance, such as, for example, the "superbonus" initiative promoted by the Italian government.

Besides the reception of sustainable retrofitting principles and the promotion of policies that can economically support their application, it clearly appears how the development of effective and efficient integrated retrofit technologies is a key aspect in order to address the aim of renovation of a rapidly aging building stock.

This work proposes an innovative integrated retrofit technology based on insulating concrete form (ICF) panels. The aim of the presented research is to highlight the main characteristics of this technology, analyzing with particular emphasis its structural behavior. The paper is organized so that, after recalling the main issues regarding the energy consumption and seismic vulnerability of existing reinforced concrete (RC) and masonry buildings, a complete description of the proposed system is provided, also analyzing its components and installation procedure. Then, attention is focused on structural aspects, 
providing and discussing strategies for structural design and numerical modeling of the retrofit system with reference to case study examples.

\section{Major Issues on Energy Consumption and Seismic Vulnerability of Existing Buildings \\ 2.1. Energy Consumption of New and Existing Buildings}

In the last decades, attention has been focused on the problem of global warming and the adverse effects on the planet induced by the exploitation of natural resources. Buildings have a paramount role in global energy consumption. According to Berardi et al. [14], in 2010, buildings accounted for $32 \%$ of total global energy use, divided into $24 \%$ for residential buildings and $8 \%$ for commercial ones. In both typologies, space heating is the primary source of energy demand (over $30 \%$ of the global consumption). It is worth noting that about $66 \%$ of the existing building stock in Europe was built before the 1970s, when the first energy codes for buildings were introduced [15]. In particular, those built after the Second World War are in general characterized by extremely poor energy performances.

Today, the EU, US, and Russia show a nearly constant rate of urbanization and new construction rate due to a stabilized socio-economic situation. The estimated ratio of building energy consumption for these countries in 2040 stands between 0.7 and 1.5 with respect to the 1970 level [14]. Zhang et al. [16] reported that China experienced a very rapid expansion of urbanization and the construction of residential buildings in recent years. From 2000 to 2016, the completed floor area of urban residential buildings increased five times, and the energy consumption grew four times. The energy consumption in the considered time range experienced a quick rise at first and then a stabilization due to economic adjustment and the implementation of new modern and engineered structural types.

According to Berardi et al. [14], developing countries are still today subjected to a continuous increase in population and urbanization. As an example, India is expected to increase the population living in cities in the next 25 years by $20 \%$. As a consequence, there will be a significant increase in energy consumption related to the building sector.

The employment of high-performance envelopes and heating, ventilation, and airconditioning (HVAC) systems can greatly improve the energy performance of buildings [17]. However, the construction process itself is now recognized as a highly energy-consuming process, especially regarding construction materials manufacturing. Therefore, a two-fold path needs to be pursued to obtain significant results in diminishing the global buildings ${ }^{\prime}$ energy demand: (i) introducing prescriptions for high-performance envelopes in national building codes of developing countries, accepting the increase in the number of buildings while limiting their energy demand; (ii) promoting and encouraging practices of retrofitting and improvement of envelope's insulation capacity of existing buildings in developed countries in order to diminish the energy consumption due to construction activities and heating/cooling processes.

\subsection{Seismic Vulnerability of Existing Masonry Buildings}

Masonry is one of the most common structural typologies for buildings that have been adopted since ancient times. Most of the residential buildings in the Mediterranean area have one or two stories and are built with brick masonry.

The structural behavior and seismic deformation capacity of masonry constructions are primarily related to the structural geometry and state of preservation. Masonry buildings should assume a box-type structural system, which in order to be effective needs strong connections between intersecting walls and rigid horizontal diaphragms. In fact, as fully recognized in the literature, masonry walls are effective in resisting in-plane actions while being more vulnerable to perpendicular loads. The box behavior allows taking care of walls' lack of resistance in the out-of-plane direction, taking advantage of the in-plane strength of perpendicular walls.

During the last decades, surveys of earthquake effects on masonry buildings allowed the identification of their typical failure mechanisms when subjected to seismic actions. 
Local failure modes are one of the primary sources of vulnerability, such as simple/complex overturning of external walls and vertical/horizontal out-of-plane bending [18-20]. The main issues that cause the activation of the cited kinematic mechanisms are lack of connection of the wall panels with floors and orthogonal walls, relevant out of plumb of walls, and masonry internal discontinuity [21,22]. Regarding the in-plane behavior, the most common observed damages are due to shear failure, which reflect in evident diagonal cracks in masonry piers and spandrels [23-25]. Brick masonry can also experience sliding failure along the horizontal mortar beds due to shear action [23]. The in-plane failure under seismic actions generally does not lead to the collapse of the structure, but it can trigger the out-of-plane kinematic mechanisms mentioned above [20].

Many repair techniques have been proposed and employed to reduce the seismic vulnerability of masonry buildings [26]. The most common techniques comprise steel tie rods and masonry buttresses [27] (to improve the connections between the walls and the out-of-plane equilibrium, respectively), local dismantling and rebuilding [27] (to restore the wall continuity along crack lines), the substitution of wooden floors with RC ones (to increment story stiffness), and thin RC layer jacketing [28] (to increase in-plane and out-of-plane strength).

The surveys took after the recent earthquakes reported that in some cases believed retrofit interventions have actually increased the vulnerability [29], although they had been realized according to the design codes effective at their time. As an example, the introduction of tie-beams at intermediate stories in the thickness of masonry often induce uneven load redistribution on masonry piers and produce damaging effects on perimeter walls. Another common retrofit mistake is the replacement of the existing timber floors with RC beams supporting hollow clay tiles floors without contextually increasing the strength of the masonry walls [30]. The recent earthquakes in Italy put in evidence that the extensive roof replacing with a heavier and stiffer structure caused the cracking of the supporting walls and often also the complete collapse of the structure [29]. This behavior was due to the increased seismic force induced by the increased mass on top of the building that acted on unreinforced walls and the contemporary reduction of energy dissipation capacity $[30,31]$. Additionally, strengthening techniques such as jacketing showed their ineffectiveness due to faulty connections and incompatibility of materials. The more recent composite material strengthening techniques, such as fiber-reinforced polymers (FRP) or glass fiber-reinforced polymers (GRP), provide high strength to the masonry panels while avoiding the negative effect of increasing the mass thanks to their small thickness and low weight.

\subsection{Seismic Vulnerability of Existing Reinforced Concrete Buildings}

Reinforced concrete structures have spread widely since the 1950s. Most of the existing $\mathrm{RC}$ structures have been designed only for vertical loads or according to now-outdated seismic regulations, since they were built before the adoption of modern seismic codes. Therefore, in most cases, there is a lack of the construction details that are needed to guarantee an adequate seismic capacity. Post-earthquake surveys and analyses of damaged or failed RC structures allowed the identification of major aspects that affect seismic vulnerability. The most common ones are quality of workmanship, low value of story stiffness as relative to other stories (soft story), location of stairs and their connection to the structure, structural typologies of floors and roofs, and steel reinforcement detailing [15]. In the following, the aforementioned aspects are briefly discussed.

The International Building Code [32] defines a soft story as a story characterized by a lateral stiffness reduction equal to $30 \%$ related to the story immediately above. In residential buildings, the typical soft story is the ground floor that hosts the garages or the store windows. The lack of infills causes increased flexibility and reduced strength, which result in extreme horizontal deflections of the story. The presence of a soft story may induce second-order effects in columns and localizations of plastic deformations that often lead to the complete collapse of RC frame buildings [33]. 
Irregularities in plan geometry (e.g., due to C or U plan shapes), eventually augmented by an eccentric position of staircases and irregular mass distribution, can lead to unwanted torsional effects [23]. Torsional vibration modes cause higher stress in perimeter structural elements that could collapse if not properly designed. These irregular plan shapes or modifications of mass distribution can also be the results of interventions of architectural renovation or changes in intended use, which hence need to be correctly designed in order to avoid and/or limit the torsional effects described above.

As is widely known, the detailing of transverse reinforcement in RC elements is fundamental to prevent collapse under seismic loads. Large stirrup spacing and poor quality of concrete lead to columns failure with the buckling of longitudinal reinforcement bars and crushing of core concrete. It is common to find open stirrups with inadequate anchorage or geometry in the older RC structures. In order to be effective, in critical zones, stirrups must have hooks with a proper length that guarantee the closure of the stirrup itself and, as a consequence, the confinement of the concrete. Properly designed stirrups act as a constraint preventing the buckling of the longitudinal rebars [34].

Inadequate design of beam-column joints, the absence of confining hoop reinforcement, and the wrong position of bar splices in columns are common causes of beam-column joint failure. Inadequate configuration of steel reinforcement in the stiffer elements, e.g., stair walls or lift shaft, could also be the cause of the failure of these structural elements, where the seismic stresses concentrate.

Other common failures observed after earthquakes are the damages and collapse of the exterior infill walls [35]. These non-structural elements are usually not adequately connected to the structure and are subjected to out-of-plane excitation. After the out-ofplane bending strength has been reached, the infill collapses, falling out of the RC frame [36]. The in-plane loaded infill panels can also experience failure due to high inter-story drifts, which cause the concentration of high compressive stresses at the infill corners. Another common failure mechanism of the infills is caused by shear stresses induced by horizontal seismic loads, similar to what happens to masonry piers and spandrels, as discussed in the previous section.

Regarding techniques for structural retrofit of RC buildings, a comprehensive review of traditional and state-of-the art methods can be found in Tsionis et al. [37] and Bournas [15]. Among most employed conventional techniques, steel or RC jacketing allows the improvement of the strength and ductility of members. However, in the case that an increased stiffness is needed, the adoption of additional shear walls could be necessary.

In the last decades, enormous efforts have been put into the study of strengthening techniques based on fiber-reinforced polymers (FRP), which are currently widespread. Some of the main drawbacks of FRP strengthening techniques include poor performance at high temperature, adhesion problems at low temperature or on wet surfaces, health issues for manual workers, and high costs, as reported by Bournas [15]. The same author pointed out that textile-reinforced mortar (TRM) strengthening techniques are now becoming increasingly important in the practice of RC members retrofitting since they overcome many of the issues encountered in FRP or steel/RC jacketing technique.

\section{Integrated Retrofitting Solutions for Existing Buildings}

Integrated retrofitting technologies aim to simultaneously solve several of the critical issues related to energy consumption and seismic vulnerability highlighted in the previous sections. Although the adoption of integrated renovation strategies has only recently become widespread, several solutions have already been proposed.

One of the first applications of the integrated retrofit was reported by Takeuchi et al. [38], who presented a case study in which energy dissipation façades have been applied to a school building, aiming to improve energy efficiency and seismic performance. The structural strengthening is obtained by seismic dissipation braces installed on the outside of the building. The outer aluminum louvers forming sunshades are fixed to the dissipation brace, forming an integrated façade with both structural and energy retrofit functions. An extensive analysis 
considering winter and summer scenarios proved the effectiveness of the new façade coupled with the existing glass closure in improving the energy demand for cooling and heating. Cyclic loading tests on reduced specimens and time-history numerical analysis showed improvements in the seismic behavior of the structure in terms of increased strength and reduction of story drift.

Another solution was presented by Feroldi et al. [39], who proposed an engineered double skin façade for an integrated renovation of buildings from the energy, architectural, and structural point of view. Particular attention was paid to the environmental impact and cost requirement. Moreover, the concepts of "exoskeleton" and holistic renovation approach have been introduced.

Labò et al. [40,41] analyzed various external retrofitting solutions and proposed a new holistic approach for the structural design procedure. The proposed approach aimed to solve architectural, energy, and structural deficiencies of buildings whilst targeting resilience, safety, and sustainability. Different external structural strengthening configurations were analyzed, from the "wall system", with strength lumped in few elements, to the optimized "grid-shell system", such as diagrids that consist of truss elements that can be adapted to any 3D shape. In the wall-type exoskeleton, the structural function is fulfilled by the walls while the energy and architectural improvement refer to the envelope. The diagrid type exoskeleton, instead, condenses both the structural and the energy retrofitting in the same structure. Two exoskeleton solutions applied to a reference RC building were analyzed. The steel diagrids are conceived as totally demountable, allowing the easy disassembly and possible reuse or recycling of the structural components. This aspect increases the sustainability of the intervention in terms of life cycle assessment, providing easier management of the construction at its end of life. Seismic performance and design procedures for exoskeleton structures have been studied by Reggio et al. [42], Labò et al. [43], and Passoni et al. [44].

The work by Manfredi and Masi [45] explored two integrated retrofitting solutions of an RC building designed only for vertical loads: the replacement of the infills and the socalled "double skin" intervention technique. The former consists of replacing hollow bricks with new elements that have better thermal and mechanical properties. The latter consists of adding on the outside of the building new infilled RC frames, structurally connected to the existing ones. The infills replacement was sufficient for structural rehabilitation in mid-low seismic hazard areas, while the double skin intervention was necessary in high seismic hazard areas.

Bournas [46] illustrated a new retrofitting method that employs TRM jacketing integrated with insulating panels to improve both the energy and seismic performance of buildings while keeping a low labor cost. The application to a case-study building was analyzed, and the evaluation of the expected annual loss related to both seismic and energy costs showed that the payback of the retrofitting intervention can be significantly reduced by adopting the proposed combined retrofitting approach.

The reported examples showed how the combined need for seismic and energy retrofitting can be effectively addressed. However, to determine the most suitable retrofitting solution, a careful evaluation should be performed for each specific case, considering building location, its existing structural type, and preservation conditions.

\section{Description of the Proposed Innovative Retrofitting System}

The retrofitting technology presented in this work follows the aforementioned principle of the double skin [45] and involves the installation of an additional structural layer on the outer surface of the building, i.e., an engineered exoskeleton [47]. The structural layer is composed of a thin reinforced concrete membrane cast on-site within a permanent formwork (ICF) made of two layers of insulating material.

In this ICF-integrated retrofitting technology, the capacity to resist seismic loads is provided by the thin $\mathrm{RC}$ layer, while the improvement in energy performance is provided by the contribution of the insulating material layers to the building insulation. The system constitutes an external envelope for the existing building, and its structure can be idealized 
as composed of vertical walls connected by horizontal spandrels. The seismic actions are transferred from the floors to the external ICF structural layers and then to the foundations.

The proposed system has several advantages. Regarding the improvement of the structural behavior, it is worth mentioning that the external position of the thin RC walls and their application to the entire perimeter of the building allows obtaining a structural system with high translational and torsional stiffness. Due to the high in-plane stiffness of the RC layers, structural displacement demands induced by seismic actions are reduced and damages to drift-sensible non-structural elements and vulnerable systems are limited for seismic events of moderate intensity. The proposed ICF technology is also efficient in retaining infill walls subjected to out-of-plane seismic actions. The exoskeleton must be connected to the diaphragms of the existing building. In order for the system to be effective in absorbing the horizontal seismic loads, the floors and roof should be provided with enough in-plane stiffness. The application of the exoskeleton to the complete perimeter of the building allows avoiding stress localization on diaphragms and reducing their stiffness demand.

For what concerns the installation aspect, it is to be underlined that the system is conceived to be applied to both RC frame and masonry buildings, operating exclusively from outside. Moreover, compared to other retrofit solutions that require several different interventions to solve the energy and seismic deficiencies of buildings, the proposed system is designed to improve both aspects in a single intervention and using a single technology, namely ICF panels.

In the following sub-sections, a detailed description of the elements that compose the system is provided, together with some insights on the installation procedure.

\subsection{Insulated Concrete Formwork}

The insulating material of the formworks has a low transmittance value, contributing to improving the building energy performance with better thermal insulation of the envelope. The energy consumption linked to the heating and cooling system is then reduced. Insulated formwork can be made of different materials to obtain the desired characteristics of thermal-acoustic insulation and reaction to fire. The thickness of the inner and the outer insulating layers can vary with respect to the climate zone and the thermal properties of the existing structures.

The specific insulated formwork considered in this work is composed of a threedimensional wire mesh that defines the thickness of the insulating and structural layers, as shown in Figure 1. The 3D wire mesh can be produced to allow various thicknesses of insulating and structural layers. The insulating materials can be chosen depending on the thermal conductivity, thermal shift, acoustic properties, and reaction to fire to be guaranteed. The formwork is produced off-site, and its structure allows to guarantee a uniform thickness for the reinforced concrete layer and the correct arrangement of the rebars. The ICF is assembled by putting the insulating material slices into the 3D wire mesh, as illustrated in Figure 1, and the final product is a formwork with a void between the two insulating layers that allows the pouring of concrete. 


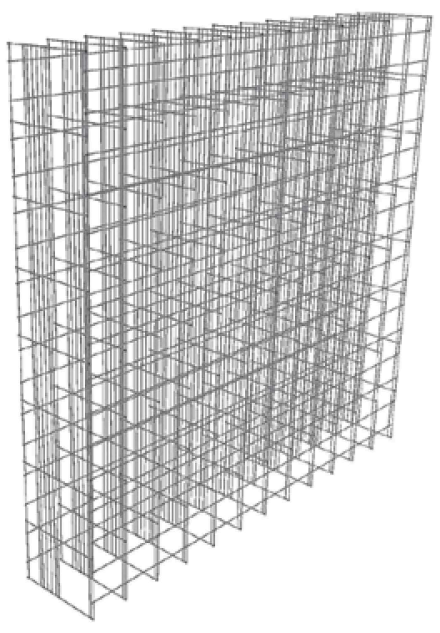

(a)

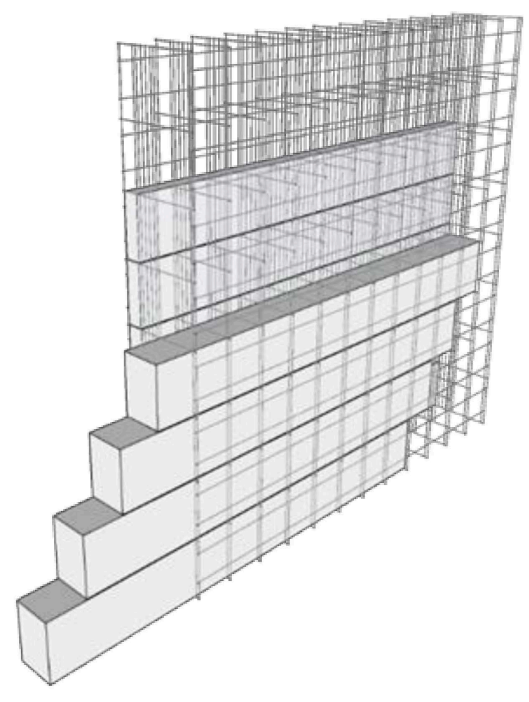

(b)

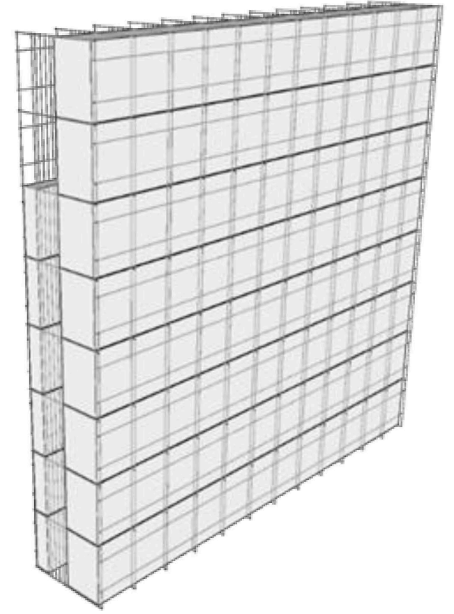

(c)

Figure 1. View of the insulated formwork: (a) three-dimensional wire mesh, (b) inserting of insulating material to create the insulating layers, and (c) assembled insulating concrete formwork.

At an initial development stage, the ICF structure consisted of the outer insulating layer and the concrete layer in direct contact with the existing structure, without the inner insulating layer. The 3D wire mesh still guaranteed the positioning of the steel rebars and the thickness of the structural layer, but the hydrostatic pressure of the fresh concrete against the existing wall (Figure 2a) made the construction operations challenging.

The introduction of the inner insulating layer bonded to the outer layer by the wire mesh allowed to compensate the hydrostatic fresh concrete pressure on the two inner surfaces of the formwork, as shown in Figure 2b. Moreover, the presence of a modular inner layer allows the creation of horizontal and vertical ribs with increased thickness.

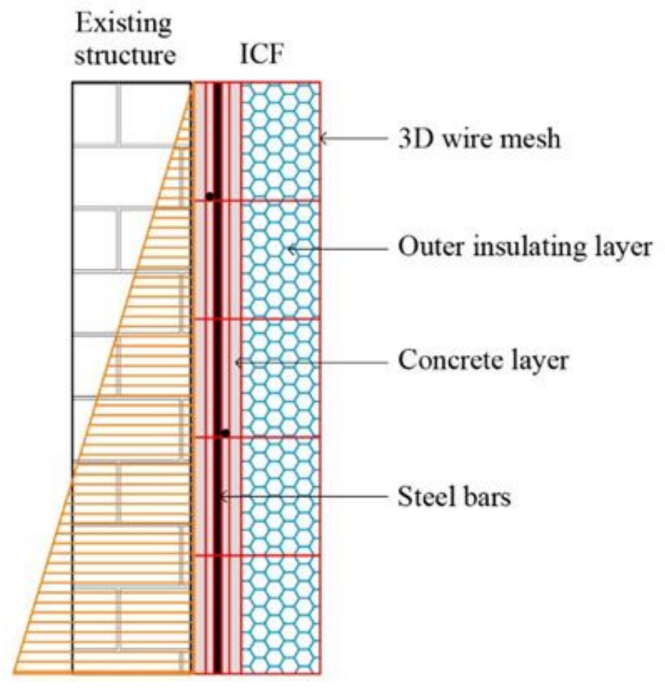

(a)

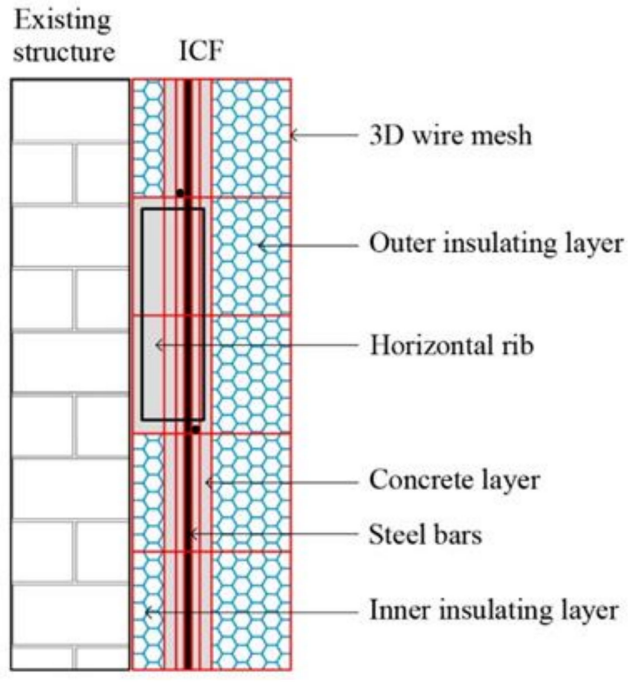

(b)

Figure 2. Development of the ICF technology: (a) initial proposal that induced hydrostatic pressure on the existing structure; (b) final proposed solution where concrete is poured within two insulating layers reciprocally constrained to eliminate the effect of hydrostatic pressure. 


\subsection{Structural Layer}

The ICF structural layer is a thin RC membrane, which is subjected almost exclusively to in-plane loads during seismic actions, considering its negligible out-of-plane stiffness. Static compression loads acting on the piers of the ICF structural layer are due to its self-weight only. The retrofit system resists only the horizontal seismic actions being mainly subjected to in-plane bending and shear actions and eventually to axial forces when working as a coupled walls system.

The reinforcement of the concrete layers consists of steel bars arranged in the longitudinal and transverse direction with defined spacing. Reinforcements can be arranged in a single layer or in two layers, depending on concrete layer thickness. In the case of small thickness, a single layer of rebars can be placed in the middle plane of the concrete layer along both vertical and horizontal directions. In this case, it is evident that transverse reinforcement cannot ensure concrete confinement and that code design details for dissipative zones in seismic resisting structures are not feasible.

At each floor level, the thickness of the concrete layer is increased to create a perimetral horizontal rib, in direct contact with the masonry or the existing curb, as shown in Figure 2b, in which it is possible to anchor the connectors effectively. The ribs also allow realizing a new reinforced concrete curb in buildings that do not have one. The localized increase in the thickness of the ICF structural layer can be obtained easily by removing a horizontal band of the inner insulating layer. In the same way, vertical ribs can be created, improving out-of-plane stiffness and guaranteeing an effective anchoring to the existing walls or columns. Figure 3 shows the ICF technology with horizontal ribs applied to different structural types.

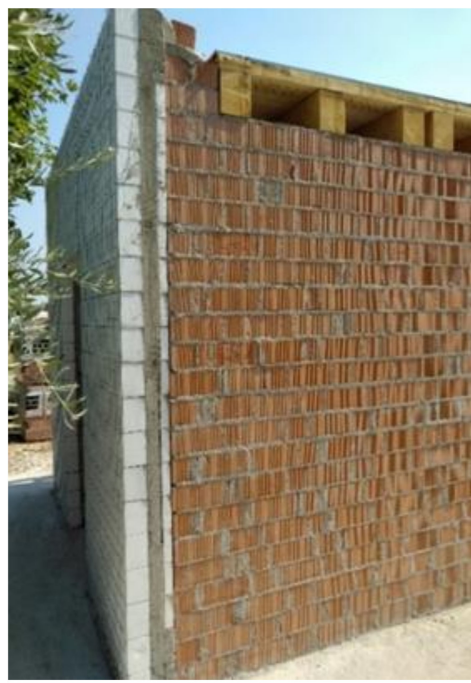

(a)

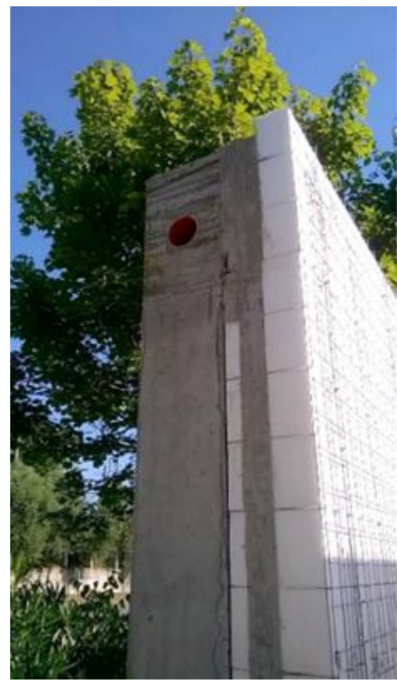

(b)

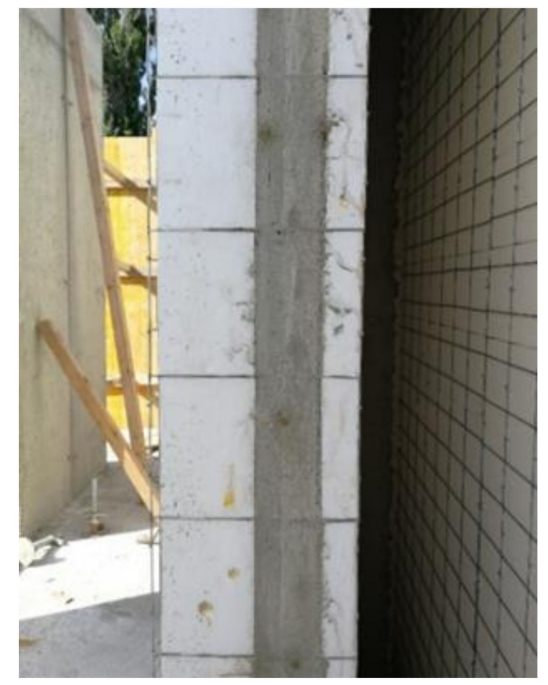

(c)

Figure 3. Concrete layer cast within the insulated formwork. (a) Application to a masonry building; (b) application to an RC frame; (c) detail of the ICF concrete layer.

\subsection{Connection System}

The retrofitting system is connected to the existing structure at each floor level, using steel connectors embedded in the horizontal ribs. The number and diameter of the connectors are designed for the expected horizontal force transferred from the floors to the exoskeleton.

For buildings with RC frame structure, the loads are transferred through shear fasteners installed on the edge beams of each floor. The fasteners can be concrete self-tapping screws, Figure $4 a$, or bent steel rebars fixed to the existing edge beams with injections of chemical mortar, Figure $4 b$. 


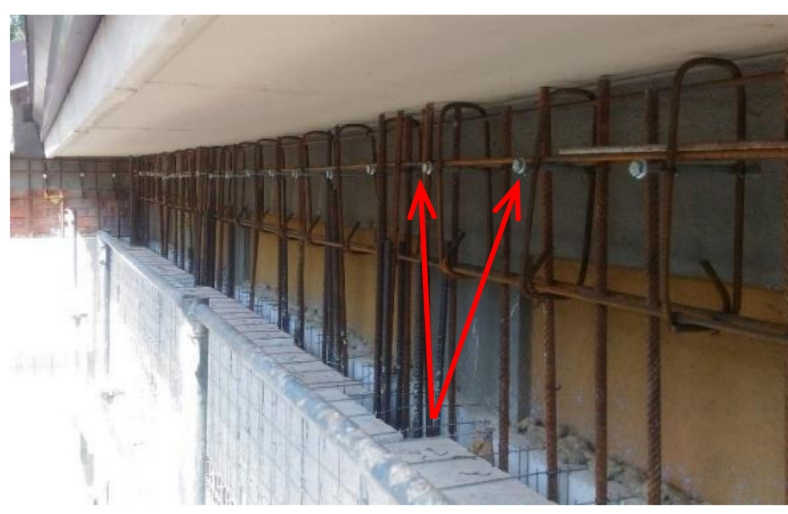

(a)

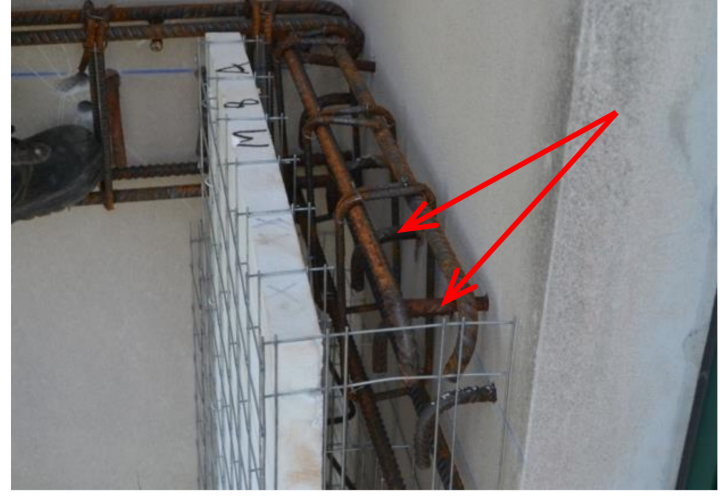

(b)

Figure 4. Connectors installed on concrete curb: (a) self-tapping concrete screws and (b) steel bars with chemical anchors.

The same approach is adopted in masonry buildings in which concrete curbs are present at the floor levels. In the case, typical of old masonry buildings with timber floors, in which concrete beams or curbs to connect the ICF structural layer are missing, a connection can be made with steel bars passing through the masonry and connected to perimetral steel profiles anchored to the existing floors. At the ground level, the ICF concrete layer is to be fixed to a foundation to transfer the seismic load to the ground. If the existing foundation system can resist the post-retrofit design seismic load, the concrete layer can be directly connected using dowels with adequate lap length. In cases where the existing foundation structure is not sufficient, it may be necessary to build a new foundation curb adjacent and anchored to the existing foundation and eventually the realization of ground anchors or micro-poles to prevent uplift phenomena.

\subsection{Installation Phases}

The ICF retrofitting technology is conceived to be applied to a wide range of building typologies, due to the possibility of producing and assembling the formwork panels of any geometry directly in the factory. The installation can be performed quickly and easily, given the lightweight of the ICF panels that facilitates their handling and installation. The main phases of the integrated retrofitting intervention with the proposed ICF technology are illustrated in Figure 5.
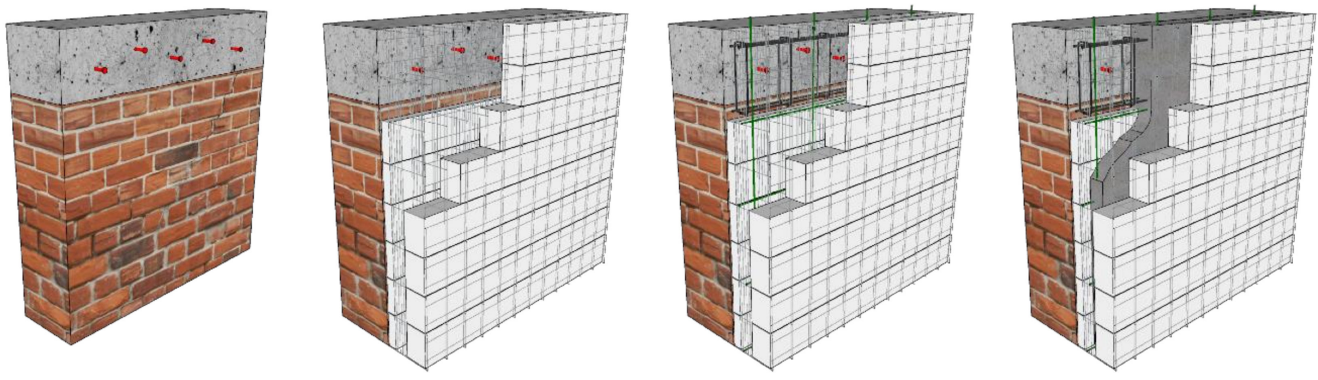

Figure 5. Construction phases of the ICF technology: installing the connectors, placing the insulated formwork, placing the steel reinforcement, and casting the concrete.

After the preliminary work, such as the enlargement of the foundation if necessary and the installation of the connection system to the foundation, the first phase consists of placing the connectors (mechanical or chemical anchors) on the perimetral edge beams, with the diameter and spacing imposed by the structural design. In this phase, it is not mandatory to remove the existing plaster, speeding up the construction times, but the connectors must be fixed to a strong structural element. Then, the ICF panels are placed against the existing walls along the perimeter of the building, starting from the ground floor, as shown in Figure 6a. Once positioned, the panels can be fixed with special anchors to the 
existing building or propped up to prevent the formwork from moving during the casting of the concrete phase. After positioning the formwork, the designed steel reinforcement is placed inside the insulated formwork. The concrete is then cast within the ICF panel, forming the structural layer and the ribs.

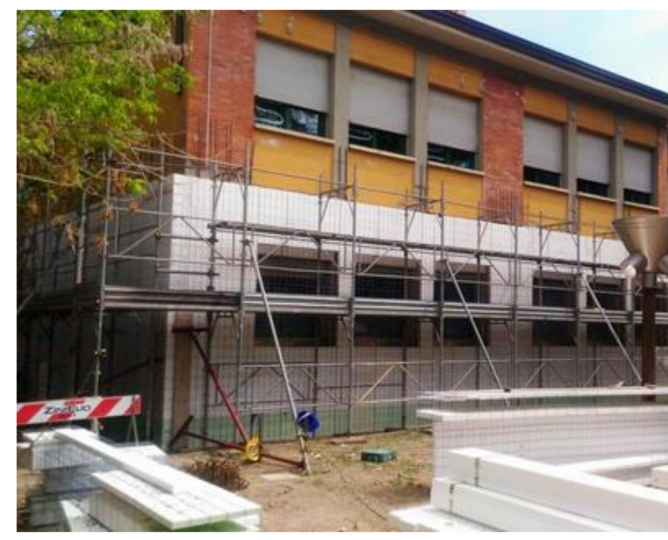

(a)

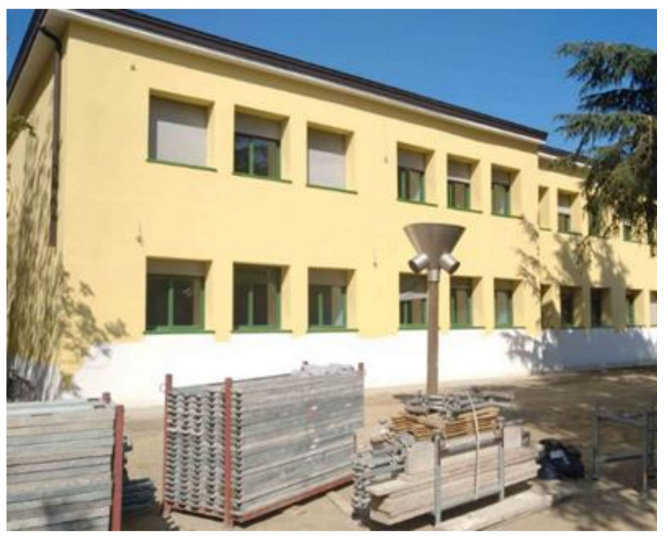

(b)

Figure 6. Installation of ICF technology on a school in Italy: (a) work in progress (b) with external finishing.

Once the ground floor is completed, the installation can move on to the first floor with the same phases and so on with the upper floors, Figure $6 \mathrm{~b}$. To guarantee the continuity of the ICF structural layer along with the entire height, the steel bars of the lower level must have an adequate lap length with the rebars that start at the upper level, see Figure 7.

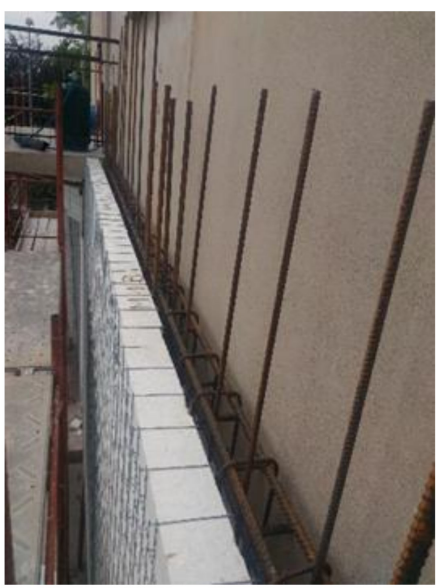

(a)

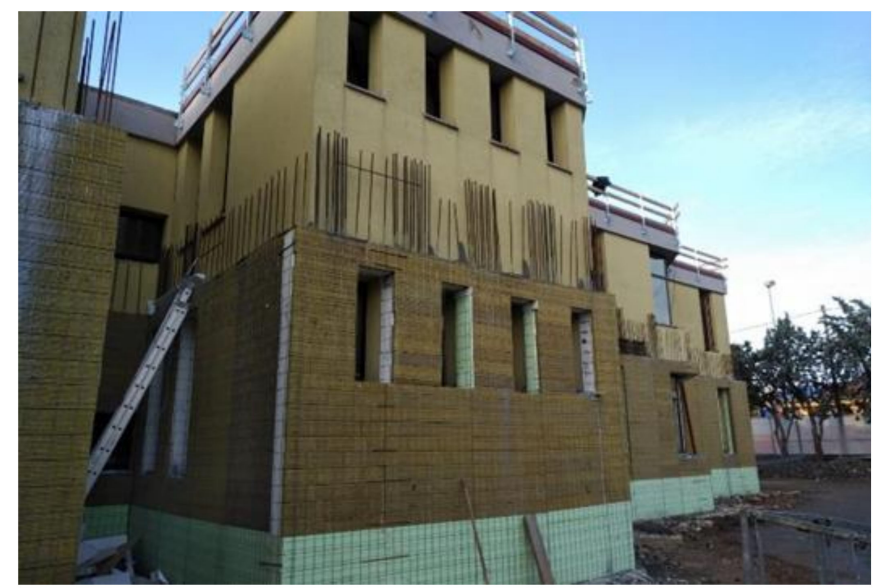

(b)

Figure 7. Examples of rebars with adequate lap length. (a) Detail; (b) global view.

\section{Analytical Structural Design for a Simple Case Study Building}

The seismic response of the thin RC layers composing the structural elements of the ICF retrofit system can be analyzed by using membrane or shell models, or by means of equivalent frame models, representing vertical piers and horizontal spandrels as beam elements connected at nodes. This second option has the main benefit of directly providing internal forces on members that can be easily compared with design strengths obtained from sectional analysis. The design of the system needs the check of resistance of both the $\mathrm{RC}$ layer and the connections between the existing structure and the exoskeleton.

Since, as mentioned before, the ICF system behaves as a non-dissipative structure, the elastic response spectra should theoretically be assumed. However, Eurocode 8 [48] 
provides a maximum seismic force reduction factor (i.e., behavior factor) of 1.5 for nondissipative structures. A quasi-elastic behavior of the section must be fulfilled, i.e., the limit strains of materials are up to yielding (for reinforcing steel) or up to the achievement of peak strength (for concrete). Prescription and detailing rules for dissipative structures are not mandatory.

In order to illustrate a procedure for the design of the proposed system, an example is provided in the following sections for a simple case study building. The described procedure, although illustrated for an elementary case study, can be generalized and applied to the design of RC layers and connections of the proposed retrofitting system in general cases.

\subsection{Description of the Case Study Building}

A one-story full-scale masonry building with a timber floor is considered as a case study for describing the design procedure of the proposed ICF retrofit system. The building, illustrated in Figures 8 and 9, was part of an experimental campaign conducted to assess the feasibility and applicability of the proposed retrofit technology $[49,50]$. Despite its simplicity, the study of this building appears to be useful since it allows the evaluation of the structural performances of the analyzed system with a fully analytical approach and then the comparison of theoretical expectations with experimental results.

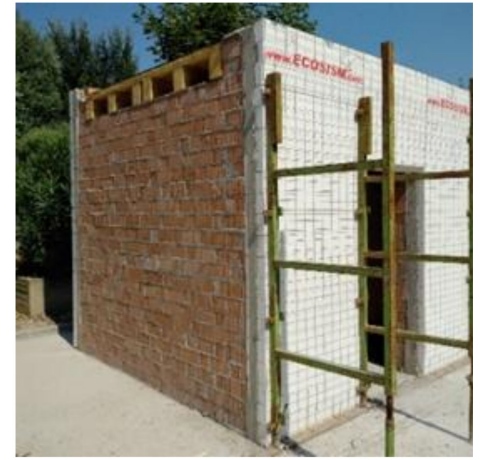

(a)

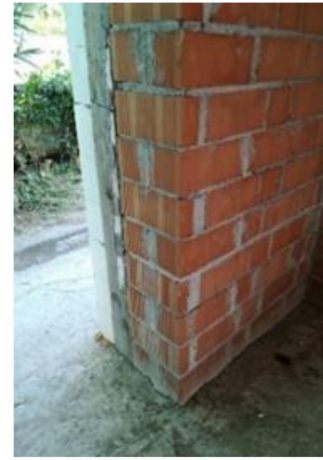

(b)

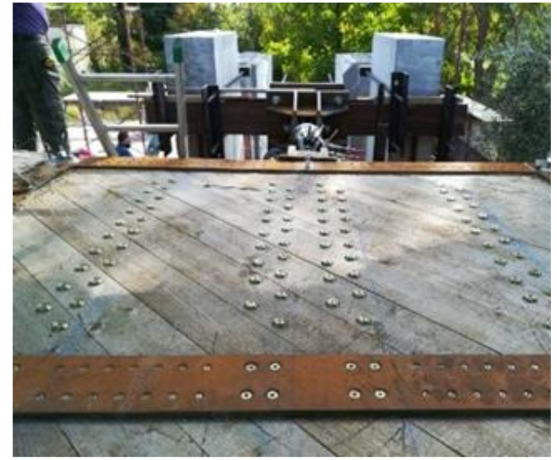

(c)

Figure 8. One-story masonry building retrofitted with the proposed ICF-based system: (a) view of the whole building; (b) view of the layers composing the retrofitted masonry wall; (c) view of the stiffened timber floor.

The building has a rectangular plan with dimensions $3.2 \times 3.0 \mathrm{~m}$ and a height of $3 \mathrm{~m}$, and it was made of multi-hole clay bricks. The longer walls, parallel to the applied horizontal load, had a centered door opening (1 $\mathrm{m}$ long and $2.1 \mathrm{~m}$ high). The roof consisted of a wooden floor with timber beams aligned with the longer side of the building, one layer of planks perpendicular to the beams, and a second stiffening layer positioned at $45^{\circ}$. The floor was connected to the walls by means of steel plates of class S355 and section $140 \times 14 \mathrm{~mm}$ (longer side direction) or $160 \times 14 \mathrm{~mm}$ (shorter side direction), as shown in Figure $9 \mathrm{~d}$. The steel plates parallel to the longer side were connected directly to the timber beams with $12 \times 160 \mathrm{~mm}$ self-tapping partially threaded screws through the two layers of timber boards.

In the direction parallel to the longer plan side, the walls were strengthened with the ICF retrofit technology. The minimum possible thickness of concrete layers was adopted, together with the minimum amount and optimum location of the steel reinforcement. The final wall section, starting from the inner toward the outer of the building, was composed of $250 \mathrm{~mm}$ brick masonry, a $40 \mathrm{~mm}$ EPS insulating layer, a $60 \mathrm{~mm}$ RC structural layer, and a $100 \mathrm{~mm}$ EPS insulating layer. The total thickness of the retrofitted walls was $450 \mathrm{~mm}$. The inner insulating layer was present for all the wall height except $300 \mathrm{~mm}$ before reaching the ground and floor levels in order to create two horizontal ribs with a cross-section of $100 \times 300 \mathrm{~mm}$. Details of reinforcement are illustrated in Figure $9 \mathrm{~b}$. The 
ribs were reinforced with four $\varnothing 6 \mathrm{~mm}$ longitudinal rebars and with $\varnothing 8 \mathrm{~mm}$ stirrups, with a spacing of $300 \mathrm{~mm}$. The concrete layer was reinforced with $\varnothing 6 \mathrm{~mm}$ vertical and horizontal rebars, with a spacing of $300 \times 300 \mathrm{~mm}$, while $\varnothing 10 \mathrm{~mm}$ rebars were placed around the door opening, on top and bottom of the RC spandrel, and at the ends of the walls. The connection of the strengthening concrete layer to the foundation slab was made using Ø16 $\mathrm{mm}$ dowel rebars with a spacing of $150 \mathrm{~mm}$ and a height above ground of $900 \mathrm{~mm}$. The concrete class used for the structural layer was C25/30, and the rebars were class B450C, according to Italian standard NTC18 [51]. The nearly rigid timber floor is connected to the ICF concrete layers through hook-shaped $\varnothing 14 \mathrm{~mm}$ B450C steel rebars, as shown in Figure 9c. The hooks are embedded in the horizontal top ribs of the ICF, while on the other end, they are welded to steel plates parallel to the longer plan side, which are fixed to the timber floor. Eight $\varnothing 14 \mathrm{~mm}$ rebars were placed on each side of the building parallel to the longer plan side, with a $45^{\circ}$ inclination with respect to the load direction, as shown in Figure 9d.

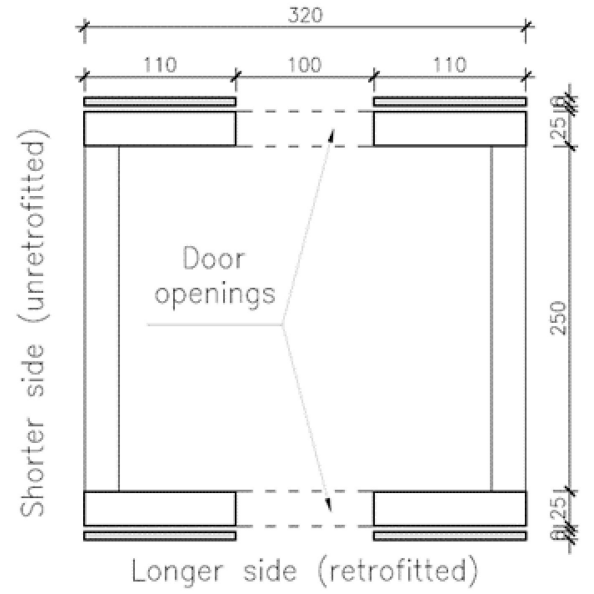

(a)

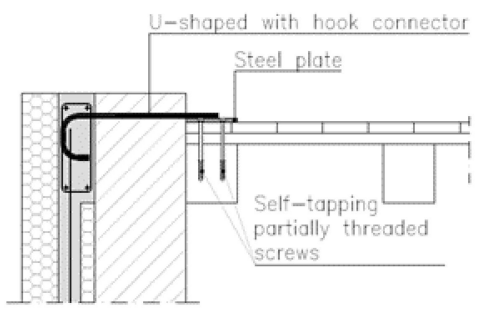

(c)

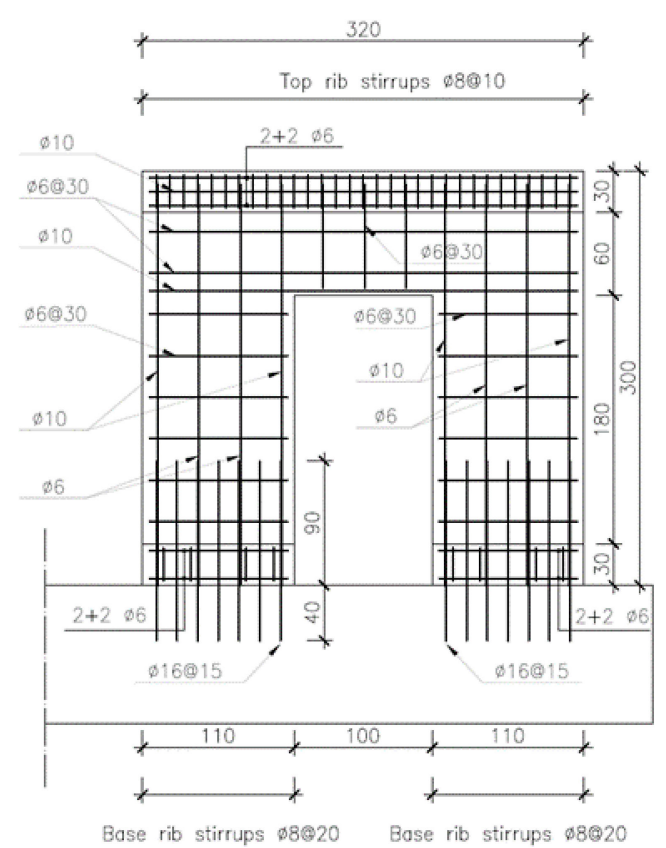

(b)

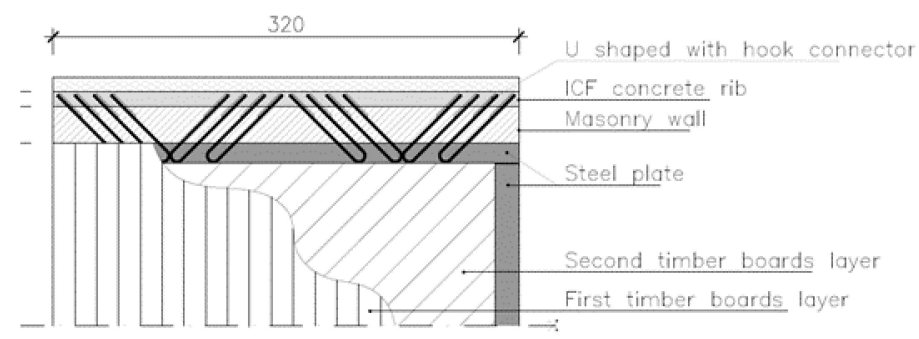

(d)

Figure 9. Details of the adopted retrofitting application: (a) horizontal section of the retrofitted specimen (b) reinforcement detailing for RC layers; (c) connection between the retrofitting system and the existing stiffened timber floor; (d) top view of timber floor and connection to the top RC rib.

\subsection{Summary of the Observed Experimental Behavior}

The case study building was subjected to an experimental loading test, also described in the work by Pertile et al. [49]. A cyclic loading protocol was adopted, as shown in Figure $10 \mathrm{a}$, with increasing value of the horizontal displacement $\delta$ imposed at the top of 
the RC walls. The load was applied along the longer side of the building, as shown in Figure 9a. The vertical RC walls underwent flexural and shear deformation, together with rotation of the base section due to partial slippage of the foundation dowels. Diagonal cracks were observed between vertical walls and the horizontal spandrel, both in masonry and RC layers. No sliding has been observed between the timber floor and the RC ribs during the experimental test, proving the connection system to be effective.

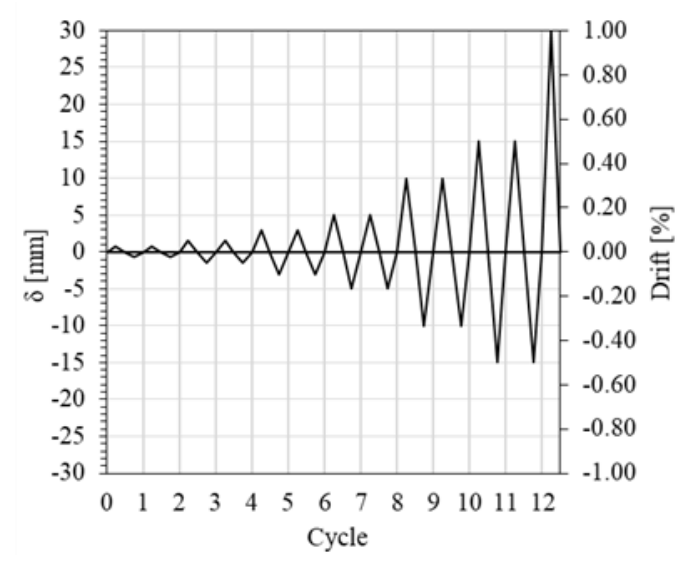

(a)

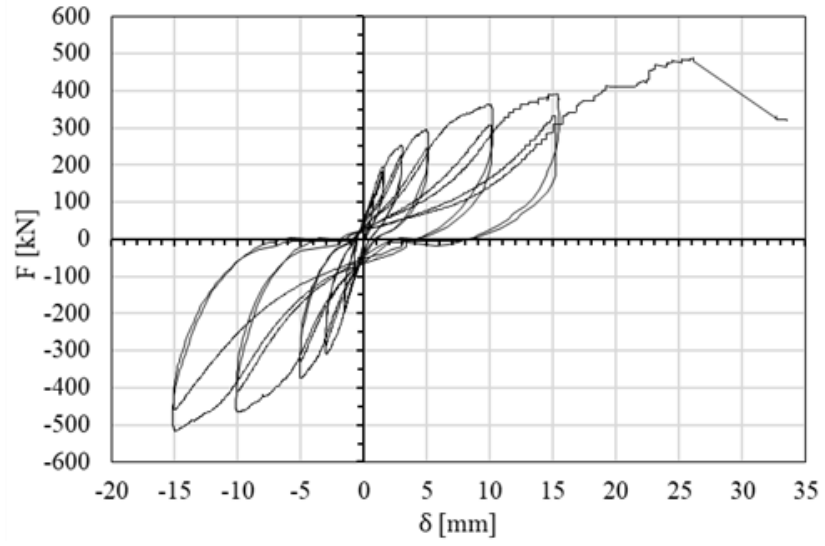

(b)

Figure 10. Experimental test on the single-story masonry building (adapted and modified from Pertile et al. [49]): (a) displacement history imposed at the top of RC walls; (b) experimental load-displacement curve for displacement $\delta$ measures at the top of the RC walls.

The force vs. displacement history from the test is reported in Figure 10b, for the horizontal displacement $\delta$ measured at the top of the RC walls. The global horizontal strength of the specimen suddenly dropped after reaching the value $F_{u, e x p}=485 \mathrm{kN}$ at a displacement $\delta_{\mathrm{u} \text {,exp }}$ equal to $26 \mathrm{~mm}$. A wide horizontal crack opened in one of the RC piers just above the end of the foundation dowel rebars where the ultimate bending strength was first achieved.

\subsection{Evaluation of Seismic Design Action}

The design seismic force was determined according to the Italian standard NTC18 [51]. The design working life $V_{N}$ was assumed to equal 50 years for building structures, while the importance factor $\gamma_{1}$ was taken equal to 1.0. Therefore, the reference return period $V_{R}$ of the seismic action was equal to 50 years. The building is assumed to be built on a flat ground, composed of deposits of loose-to-medium cohesionless soil or predominantly soft-to-firm cohesive soil (i.e., soil type D according to NTC18 [51]). According to these characteristics, a $5 \%$ damped elastic response spectrum was generated, whose main parameters are reported in Table 1.

Table 1. Elastic response spectrum parameters.

\begin{tabular}{ccc}
\hline Parameter & Symbol & Value \\
\hline $\begin{array}{c}\text { Reference peak ground acceleration for rigid soil } \\
\text { Soil amplification factor }\end{array}$ & $\mathrm{a}_{\mathrm{g}}$ & $0.083 \mathrm{~g}$ \\
reference site & $\mathrm{S}$ & 1.8 \\
Maximum spectral amplification to the horizontal rigid & $\mathrm{F}_{0}$ & 2.636 \\
Period at which the constant acceleration branch begins & $\mathrm{T}_{\mathrm{B}}$ & $0.241 \mathrm{~s}$ \\
Period at which the constant velocity branch begins & $\mathrm{T}_{\mathrm{C}}$ & $0.723 \mathrm{~s}$ \\
Period at which the constant displacement branch begins & $\mathrm{T}_{\mathrm{D}}$ & $1.9 \mathrm{~s}$ \\
Damping modification factor & $\eta$ & 1.0 \\
\hline
\end{tabular}


A design inelastic response spectrum was obtained dividing the elastic spectrum ordinates by a factor equal to 1.5, according to Eurocode 8 [48] for non-dissipative structures. Assuming the building fundamental period $\mathrm{T}_{1}$ to belong to the spectrum plateau range (i.e., $\left.\mathrm{T}_{\mathrm{B}}<\mathrm{T}_{1}<\mathrm{T}_{\mathrm{C}}\right)$, the design seismic acceleration $\mathrm{S}_{\mathrm{d}}\left(\mathrm{T}_{1}\right)$ has been evaluated as:

$$
\mathrm{S}_{\mathrm{d}}\left(\mathrm{T}_{1}\right)=\mathrm{ag}_{\mathrm{g}} \cdot \mathrm{F}_{0} \cdot \mathrm{S} / \mathrm{q}=0.262 \mathrm{~g}
$$

Considering only the weight of the upper half part of the vertical elements, the seismic weight of the retrofitted building is equal to $\mathrm{W}=114.6 \mathrm{kN}$, of which only about $11 \%$ is imputable to the added ICF system. The corresponding design value of the seismic base shear $\mathrm{F}_{\mathrm{Ed}}$ is:

$$
\mathrm{F}_{\mathrm{Ed}}=(\mathrm{W} / \mathrm{g}) \cdot \mathrm{S}_{\mathrm{d}}\left(\mathrm{T}_{1}\right)=30 \mathrm{kN}
$$

which is about $1 / 16$ of the experimentally measured strength. It is worth pointing out that in this elementary case study building, even though a minimum amount of reinforcement and minimum concrete thickness have been adopted for the retrofitting system, the observed experimental strength is significantly higher than the design seismic base shear. This fact highlights how, even in real buildings, the presented retrofitting system can provide a significant contribution to the horizontal load-carrying capacity, with a very slight seismic mass increment.

\subsection{Design of the RC Layers}

In this section, approaches and formulations for the calculation of bending and shear strengths of RC members of the retrofitting system are presented, considering the quasielastic behavior assumption.

Bending resistance $\mathrm{M}_{\mathrm{R}}$ can be calculated through classical sectional analysis with the assumption of preservation of plane section and limiting ultimate materials strains to the elastic range. Calculation needs to take into account the actual axial load $\mathrm{N}_{\mathrm{E}}$.

The calculation of the shear resistance of RC members is based on the Eurocode 2 [52] truss model that considers two resisting mechanisms, related to the failure of concrete struts and steel reinforcement ties, respectively related to the failure of concrete struts and steel reinforcement ties, as shown in Figure 11.

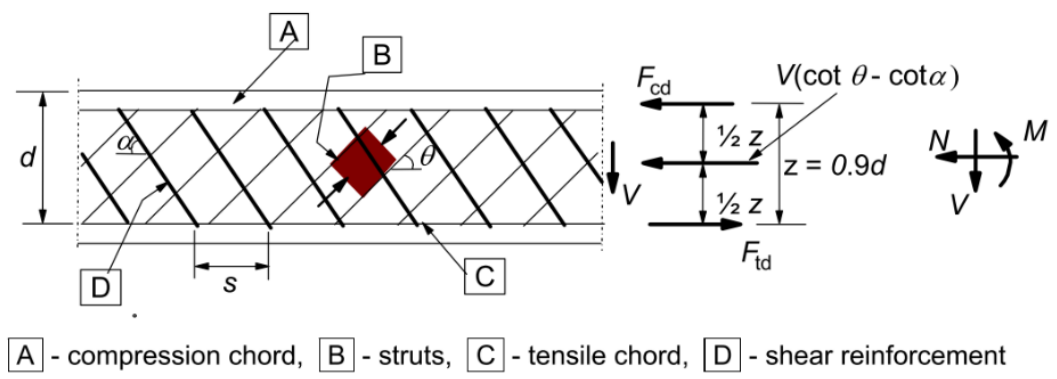

Figure 11. Truss model and notation for shear reinforced members according to Eurocode 2 [52].

The shear resistance $V_{R}$ is the smallest value between the shear-tensile strength $V_{R, t}$, Equation (3), and the shear-compressive strength $V_{R, c}$, Equation (4).

$$
\begin{gathered}
V_{R, t}=A_{s w} / s \cdot z \cdot f_{y w} \cdot(\cot \theta+\cot \alpha) \cdot \sin \alpha \\
V_{R, c}=\alpha_{c w} \cdot b_{w} \cdot z \cdot v_{1} \cdot f_{c} \cdot(\cot \theta+\cot \alpha) /\left(1+\cot ^{2} \theta\right)
\end{gathered}
$$

The sliding shear resistance $V_{R, s}$ is calculated according to Eurocode 2 [52] using Equations (5)-(8), where $V_{d}$ is the resistance of the vertical dowel rebars, $V_{i}$ is the shear resistance of inclined bars (null in the specific case), and $V_{f}$ is the friction resistance 
(meaning of uncited symbols can be found in Eurocode 2 [52]). The potential sliding plane considered in calculations is located at the critical section of the piers.

$$
\begin{gathered}
\mathrm{V}_{\mathrm{R}, \mathrm{s}}=\mathrm{V}_{\mathrm{d}}+\mathrm{V}_{\mathrm{i}}+\mathrm{V}_{\mathrm{f}} \\
\mathrm{V}_{\mathrm{d}}=\min \left[1.3 \cdot \Sigma \mathrm{A}_{\mathrm{sj}} \cdot \sqrt{ }\left(\mathrm{f}_{\mathrm{c}} \cdot \mathrm{f}_{\mathrm{y}}\right) ; 0.25 \cdot \mathrm{f}_{\mathrm{y}} \cdot \Sigma \mathrm{A}_{\mathrm{sj}}\right] \\
\mathrm{V}_{\mathrm{i}}=\Sigma \mathrm{A}_{\mathrm{si}} \cdot \mathrm{f}_{\mathrm{y}} \cdot \cos \varphi \\
\mathrm{V}_{\mathrm{f}}=\min \left[\mathrm{\mu}_{\mathrm{f}} \cdot\left[\left(\Sigma \mathrm{A}_{\mathrm{sj}} \cdot \mathrm{f}_{\mathrm{y}}+\mathrm{N}_{\mathrm{E}}\right) \cdot \xi+\mathrm{M}_{\mathrm{E}} / \mathrm{z}\right] ; 0.5 \cdot \eta \cdot \mathrm{f}_{\mathrm{c}} \cdot \xi \cdot \mathrm{l}_{\mathrm{w}} \cdot \mathrm{b}_{\mathrm{w} 0}\right]
\end{gathered}
$$

In the analyzed case study, the RC walls can be schematized with an equivalent frame model, as represented in Figure 12b, where each wall consists of two vertical piers and a horizontal spandrel. The spandrel is considered to behave as a rigid connection for the piers. According to experimental observations, the critical section of piers (i.e., the section that first reaches the ultimate condition according to one of the possible above-described failure mechanisms) is set just above the end of the dowel reinforcement.

The distribution of internal forces induced by the horizontal load applied at the rigid floor level can then be derived in accordance with the scheme shown in Figure 12b. It allows the derivation, in first approximation, of the global horizontal force associated with the crisis of RC piers, neglecting the contribution provided by the masonry elements.

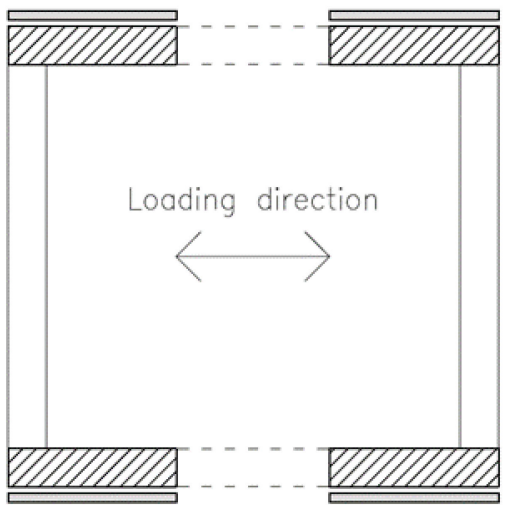

(a)
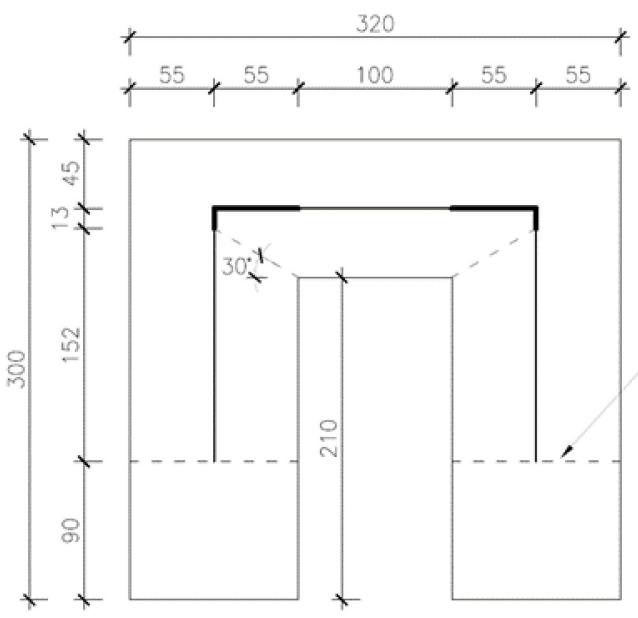

(b)

Figure 12. Scheme for calculation of the seismic strength capacity: (a) horizontal section of resisting piers and (b) equivalent frame scheme for RC walls.

In particular, in the case of bending failure of the RC piers, the global horizontal strength may be expressed as a function of the resistant moment $M_{R}$ of the critical section as follows:

$$
\mathrm{F}_{\text {flex }}=4 \cdot\left(2 \cdot \mathrm{M}_{\mathrm{R}} / \mathrm{h}^{*}\right)
$$

The height $\mathrm{h}^{*}=1.52 \mathrm{~m}$ is the height of the RC piers measured from the lower end of the pier-spandrel node down to the actual critical section of each pier.

In the case of shear failure or sliding shear failure of the piers, the associated global horizontal strength can be obtained, respectively, according to the relations:

$$
\begin{gathered}
\mathrm{F}_{\text {shear }}=4 \cdot \mathrm{V}_{\mathrm{R}} \\
\mathrm{F}_{\text {sliding }}=4 \cdot \mathrm{V}_{\mathrm{R}, \mathrm{s}}
\end{gathered}
$$

Finally, the ultimate horizontal force $\mathrm{F}_{\mathrm{R}}$ that can be resisted by the building is:

$$
\mathrm{F}_{\mathrm{R}}=\min \left[\mathrm{F}_{\text {flex }}, \mathrm{F}_{\text {shear }}, \mathrm{F}_{\text {sliding }}\right]
$$


In the calculation of the ultimate strengths of the critical section of the RC piers, it is necessary to take into account the contribution of the axial force $\mathrm{N}_{\mathrm{E}}$, which is due in part to gravitational loads $\left(\mathrm{N}_{\text {gravity }}\right)$ and in part to the coupling between the piers guaranteed by the rigid spandrel ( $\mathrm{N}_{\text {coupling }}$ ). According to the scheme described in Figure 12, the latter contribution can be determined as follows:

$$
\mathrm{N}_{\text {coupling }}= \pm \mathrm{k} \cdot\left(\mathrm{F}_{\mathrm{E}} / 2\right) \cdot \mathrm{h}^{*} / \mathrm{L}_{\mathrm{f}}
$$

where $L_{f}=2.1 \mathrm{~m}$ is the distance between the axis of the piers and $\mathrm{k}=0.5$ with the assumption of the rigid spandrel. Equation (13) shows how the axial load due to the coupling effect actually depends on the global horizontal load $\mathrm{F}_{\mathrm{E}}$ acting at the floor level. Therefore, the calculation of strength for resisting mechanisms that rely on axial load contributions would theoretically need to be performed iteratively.

\subsection{Design of the Connection System}

The RC layers of the retrofit system are connected to the existing building at the floor level, by means of steel rebars, as indicated in Figure 9. The load transfer capacity of the connection depends on the bond between steel rebars and the surrounding concrete. For a single rebar, the ultimate bond strength $F_{b}$ is calculated using Equations (14)-(17), where $\Phi$ is the bar diameter and $l_{b}$ is the anchorage length. The ultimate bond stress $f_{b}$ is calculated according to Eurocode 2 [52] using Equation (15), where $\eta_{1}$ is a coefficient related to the quality of the bond condition, $\eta_{2}$ is a coefficient related to the bar diameter, and $f_{c t}$ is the value of concrete tensile strength. The yielding strength of the steel bar $F_{s}$ is calculated with Equation (16). The ultimate resistance of each connector $F_{a}$ is then evaluated as the minimum value between $F_{b}$ and $F_{s}$, Equation (17).

$$
\begin{gathered}
\mathrm{F}_{\mathrm{b}}=\pi \cdot \Phi \cdot \mathrm{l}_{\mathrm{b}} \cdot \mathrm{f}_{\mathrm{b}} \\
\mathrm{f}_{\mathrm{b}}=2.25 \cdot \eta_{1} \cdot \eta_{2} \cdot \mathrm{f}_{\mathrm{ct}} \\
\mathrm{F}_{\mathrm{s}}=\mathrm{A}_{\mathrm{s}} \cdot \mathrm{f}_{\mathrm{y}} \\
\mathrm{F}_{\mathrm{a}}=\min \left[\mathrm{F}_{\mathrm{b}}, \mathrm{F}_{\mathrm{s}}\right]
\end{gathered}
$$

For the present case study, the global resistance of the connection system along with the loading direction $\mathrm{F}_{\text {connection }}$ can be computed considering all the resisting elements inclined at $45^{\circ}$ according to Equation (18), where $n_{a}$ is the total number of connectors:

$$
\mathrm{F}_{\text {connection }}=\mathrm{n}_{\mathrm{a}} \cdot \mathrm{F}_{\mathrm{a}} / \sqrt{ } 2
$$

\subsection{Discussion}

The presented design approaches can be employed to provide an estimation of the ultimate strength of the retrofitting system applied to the present case study building. A calculation has been performed adopting some simplifications; namely, the contributions of the masonry structure in terms of stiffness and ultimate strength have been neglected, allowing dealing with simple analytical formulations for building global strength evaluation. Moreover, by neglecting the masonry strength contribution, it was possible to highlight the resistance of the retrofitting system alone. Calculations been performed adopting an elastic-perfectly plastic law for steel and a parabola-rectangle law for concrete.

In the first instance, design values for material strengths are employed in calculations, obtaining values for steel and concrete strengths according to Italian standard NTC18 [51] equal to $\mathrm{f}_{\mathrm{yd}}=391.3 \mathrm{MPa}$ and $\mathrm{f}_{\mathrm{cd}}=14.17 \mathrm{MPa}$, respectively. Values for steel elastic modulus $\mathrm{E}_{\mathrm{S}}=206,000 \mathrm{MPa}$ and concrete strain at maximum strength $\varepsilon_{\mathrm{c} 2}=2 \%$ have been adopted. Considering a non-dissipative material behavior, steel ultimate tensile strain $\varepsilon_{\mathrm{su}}$ has been adopted equal to the steel yielding strain, while ultimate concrete compressive strain $\varepsilon_{\mathrm{cu}}$ has been adopted as equal to $\varepsilon_{\mathrm{c} 2}$. The strength calculations for RC piers failure mechanisms have been performed taking into account for the axial load contributions due to the coupling 
effect provided by the spandrel, considering as vertical dead loads only those due to the self-weight of the ICF panels. The negligible strength contribution of the steel wires of the formwork was disregarded.

In Table 2, a brief resume of the obtained minimum strengths is given. The minimum design global strength is associated with the bending failure of the RC piers with tensile axial load due to coupling. The design ultimate load of the system corresponds to $27 \%$ of the actual ultimate load experimentally obtained $(485 \mathrm{kN})$. It is also worth noting that the obtained design strengths are all largely greater than the design seismic action $(30 \mathrm{kN})$ evaluated in Section 5.3, even if minimum reinforcement and concrete layer thickness were adopted in the presented retrofitting application.

Table 2. Comparison of horizontal strength values according to the different possible failure mechanisms evaluated using design material strengths and non-dissipative behavior.

\begin{tabular}{cccc}
\hline Failure Mechanism & $\begin{array}{c}\text { Design } \\
\text { Pier Strength } \\
(\mathbf{k N})\end{array}$ & $\begin{array}{c}\text { Design } \\
\text { Overall Strength } \\
(\mathbf{k N})\end{array}$ & $\begin{array}{c}\text { Design/Experimental } \\
\text { Overall Strength } \\
\mathbf{( \% )}\end{array}$ \\
\hline Flexural failure of RC piers & 33.19 & 132.74 & 27 \\
Shear failure of RC piers & 82.15 & 328.60 & 68 \\
Sliding shear failure of RC piers & 44.16 & 176.65 & 36 \\
Failure of the connection system & 120.61 & 482.45 & 99 \\
\hline
\end{tabular}

In order to provide a comparison with the experimentally measured global horizontal strength of the building, its analytical counterpart was calculated using the scheme described in Section 5.5, considering the mean experimental values of material strengths and material constitutive laws that consider plastic deformations (i.e., considering a dissipative material behavior). Experimental mean values for steel yielding strength, $\mathrm{f}_{\mathrm{ym}}=555 \mathrm{MPa}$, and concrete compressive strength, $\mathrm{f}_{\mathrm{cm}}=35.2 \mathrm{MPa}$, have been retrieved during the experimental campaign on the case study building. Ultimate strains for steel and concrete are assumed to be equal to $\varepsilon_{\mathrm{su}}=75 \%$ and $\varepsilon_{\mathrm{cu}}=3.5 \%$, respectively. The obtained values are reported in Table 3 together with the consequent analytical global mean strengths of the entire building.

Table 3. Comparison of horizontal strength values according to the different possible failure mechanisms evaluated using mean experimental material strengths and dissipative behavior.

\begin{tabular}{cccc}
\hline Failure Mechanism & $\begin{array}{c}\text { Design } \\
\text { Pier Strength } \\
(\mathbf{k N})\end{array}$ & $\begin{array}{c}\text { Design } \\
\text { Overall Strength } \\
(\mathbf{k N})\end{array}$ & $\begin{array}{c}\text { Design/Experimental } \\
\text { Overall Strength } \\
\mathbf{( \% )}\end{array}$ \\
\hline Flexural failure of RC piers & 109.42 & 437.66 & 90 \\
Shear failure of RC piers & 116.52 & 466.08 & 96 \\
Sliding shear failure of RC piers & 102.45 & 409.78 & 84 \\
Failure of the connection system & 241.65 & 966.59 & 199 \\
\hline
\end{tabular}

Results based on mean properties suggest that the failure of the system was actually governed by a shear-flexural mechanism in the RC piers. Theoretical mean flexural and shear capacities are quite well-aligned with the experimental result, the rations with respect to experimental peak force being, respectively, $90 \%$ and $96 \%$. The calculated sliding strength appears a little bit underestimated since it corresponds to $84 \%$ of the recorded load. Installed connections were exuberant with respect to the need, their strength capacities being nearly double the flexural and shear strengths.

It can be concluded indeed that the proposed procedure provides safe-side results and can be successfully employed for the design of the retrofitting intervention with the ICF system.

In the presented analytical calculation, the contribution of masonry was disregarded because it is negligible with respect to that provided by the RC walls. However, more 
sophisticated numerical modeling taking into account the existing structure could be used, which can provide a better estimation of the ultimate strength of the retrofitted system and also evaluate residual strength and deformation demands on the existing structure. Examples of the detailed modeling approach are provided in the next section.

\section{Numerical Modeling Strategy and Application to Complex Buildings}

In this section, insights on strategies for the modeling and seismic analysis of buildings retrofitted with the proposed ICF-based system are presented. In particular, two case study applications are described, considering a city Hall and an educational facility, which can be both considered as strategic structures. In Mediterranean countries, several of these buildings have been built as masonry or concrete frame structures and many of them are characterized by poor seismic capacity in their actual state so that retrofit interventions are strongly needed.

Due to the specific use of strategic structures, it is almost unfeasible to temporarily free the buildings to implement the structural retrofitting. For these constructions, suitable retrofit strategies are needed that involve minimal interferences with the inside activities. The ICF retrofit system presented in this work appears to be an optimal solution for this type of intervention because it even allows the improvement of the passive energy performance of the opaque envelope at the same time.

\subsection{Case Study: City Hall Building}

This case-study building, located in Seravezza (Italy), is a city Hall building composed of several portions, which have been built in different periods. In Figure 13, the different parts that compose the building are identified.

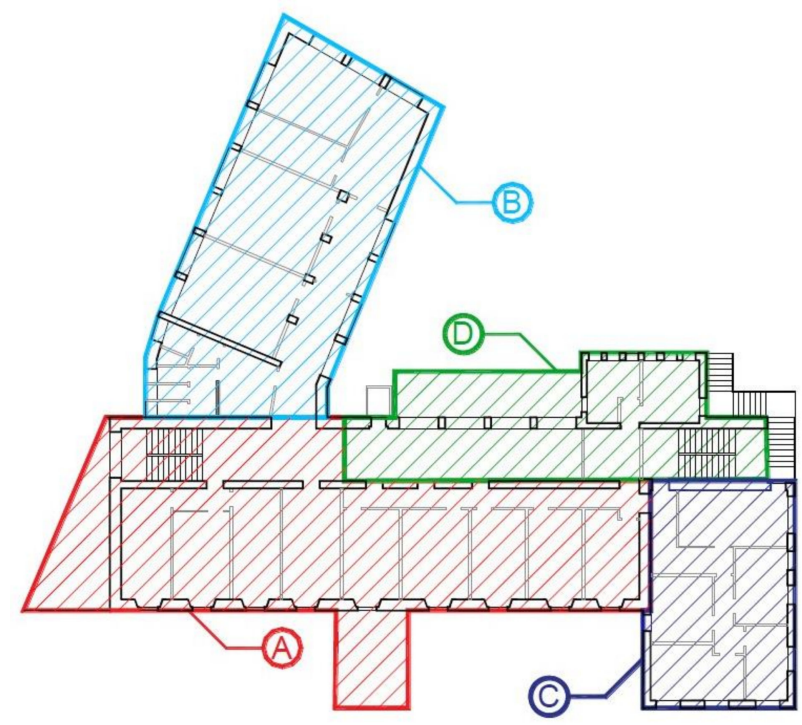

Figure 13. Plan view of the city Hall building.

The structure was first built before the 1930s with a masonry structure. The portion highlighted in red in Figure 13, Part A, is the only part of the original building that remains today. In fact, in the 1960s, the building was partially demolished and then enlarged. In particular, Part B consists of a three-story RC frame building with a flat roof. Part C also has an $\mathrm{RC}$ frame structure and three stories, but with a timber hip roof. Part D rises where the original building was partially demolished and has an RC frame structure that is connected to the masonry walls. Different floor types are present; namely, precast reinforced concrete and hollow tiles mixed floor and reinforced concrete slab floor. Due to their typologies, all floors can be assumed to be rigid diaphragms in the seismic analysis.

Figure 14 shows a three-dimensional model of the building, developed using a building information modeling (BIM) commercial software. The model not only allows an 
understanding of the actual elevation of the different portions but also allows the integration of the structural/architectonical design with the mechanical system renovation design.

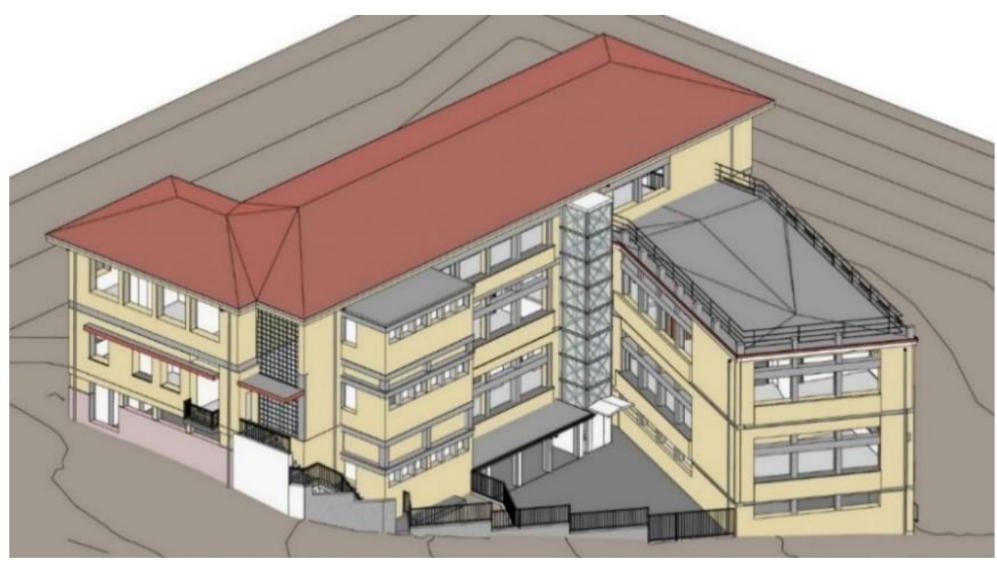

Figure 14. 3D view of the BIM model.

The elevation structures appear in a poor conservative state, mainly due to the lack of maintenance and the environmental aggressivity. Specifically, Part D is oriented to the north and presents exposure of the steel rebars of RC structures with evidence of corrosion phenomena. From the vulnerability assessment analysis, it emerged that the masonry walls of the oldest part did not have sufficient in-plane strength to resist horizontal seismic load. Moreover, RC frame structures of the newest parts were designed before the introduction of modern seismic design codes; thus, proper details to guarantee an adequate seismic performance are lacking both in members and in beam-column joints. Another critical aspect is the inadequate connection details between the different parts of the building, which did not guarantee a global box-like behavior and can induce damages due to pounding.

The building conditions require strengthening intervention in a large number of structural elements. The complex plan distribution and the different construction types connected together make the seismic retrofitting design challenging. The reinforcement of single columns and beams with traditional techniques, such as steel or FRP jacketing, was impossible to apply due to the interferences with internal wall distribution and to the high costs related to demolition and reconstruction of non-structural elements. In this context, the adopted retrofit concept was to integrate the existing structural elements (which support vertical weights) with a new system (which resists horizontal loads). The new seismic-resistant structure was conceived to coat the elevation and connect all the parts together. Using the ICF retrofit technology, the thermal insulation of the external walls was also fulfilled. The designed energy retrofitting also involves the installation of photovoltaic panels and the replacement of boilers with heat pumps.

Finite element models of the building in both present and retrofitted conditions were developed using the commercial software Midas Gen [53]. First, the existing RC frame was modeled with beam elements, while the existing masonry walls were modeled with plate elements, as shown in Figure 15a. Then, the ICF concrete layer was modeled with plate elements that have the thickness of the concrete layer, Figure 15b,c. To consider the effective contribution of the existing structure, a halved elastic modulus was used for existing concrete and masonry elements to account for cracking effects. The ICF concrete layer was modeled using an elastic constitutive law for concrete, with full elastic modulus. 


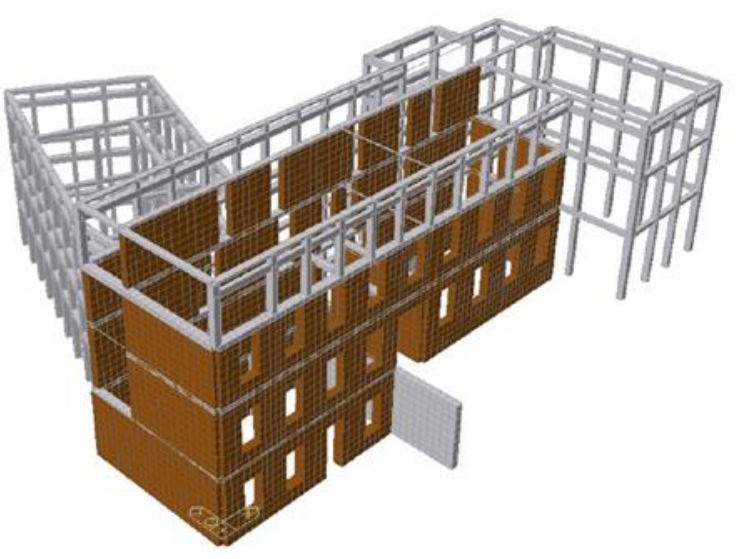

(a)

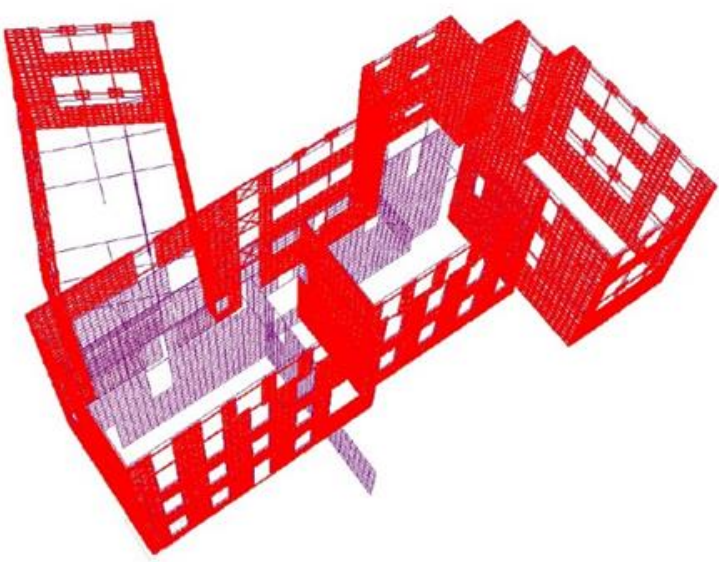

(c)

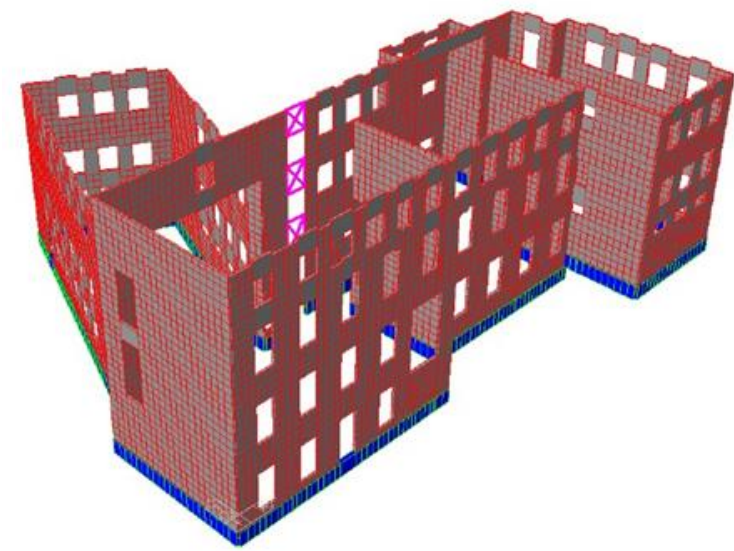

(b)

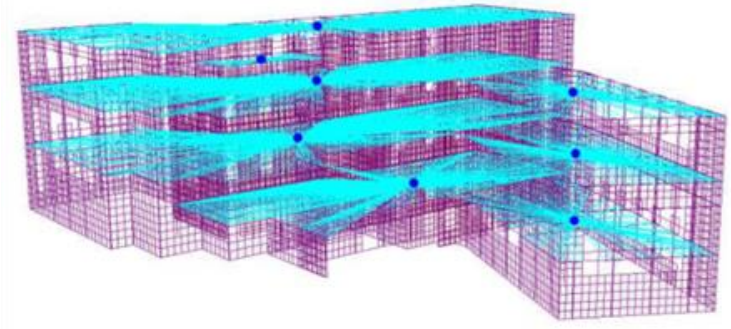

(d)

Figure 15. Numerical model for the retrofitting design: (a) existing structure; (b) ICF concrete layers; (c) existing structure and ICF concrete panels highlighted in red; (d) rigid diaphragm with mass center.

Rigid diaphragm restraint was imposed at each floor by connecting the floor center of mass to perimeter nodes of the same floor using rigid links, as shown in Figure 15d. Due to the irregular plan and different ages of the building parts, the floors of Part B were considered independent from the others but connected with truss elements. The separated floors allowed catching the independent modes of vibration of Part B and forces on the truss elements. The masses, calculated for each story, were modeled as concentrated in the center of mass at the corresponding level. A Winkler foundation was considered at the base of the structure.

The connections of the rigid stories to the new ICF structural layer were modeled with a truss element for each side connecting the corner node of the existing diaphragm with the opposite corner node of the RC membrane, as shown in Figure 16a. Analogous elements were created to simulate the connections between ICF membrane and existing columns, see Figure 16b. Trusses were provided with axial stiffness equivalent to the shear stiffness of the steel connectors disposed along each alignment. 


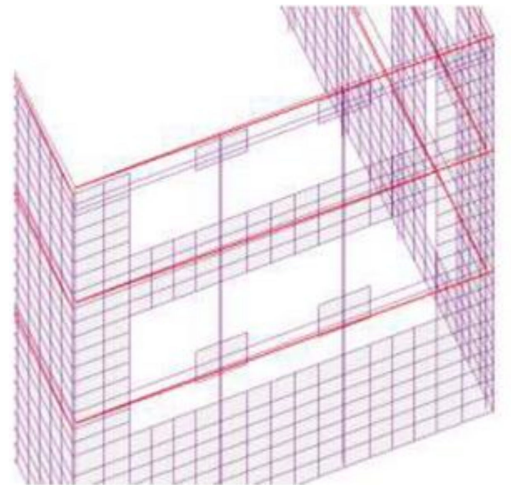

(a)

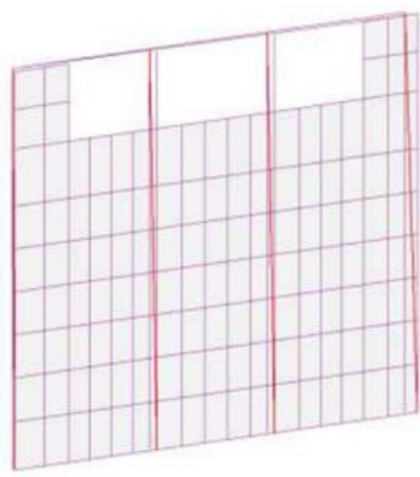

(b)

Figure 16. Trusses connecting existing structures and added exoskeleton: (a) horizontal connections along ring curbs, (b) vertical connections on existing RC columns.

Modal analyses were performed before and after the retrofitting (i.e., both not considering and considering the added exoskeleton). Obviously, the retrofitted structure was largely more rigid than the original one, as demonstrated by the vibration periods reported in Table 4. In the retrofitted configuration, existing and added structures showed common modal shapes and periods, demonstrating that the elongation of the truss elements (i.e., shear deformation of the steel connectors) was negligible with respect to the lateral drift at each story and that steel connectors can be assumed as infinitely rigid (with respect to the lateral stiffness of walls).

Table 4. Modal analysis results for city Hall building.

\begin{tabular}{cccccc}
\hline Model & Mode & Frequency (Hz) & Period (s) & $\begin{array}{c}\text { Principal } \\
\text { Component }\end{array}$ & $\begin{array}{c}\text { Modal Participation Mass } \\
\text { for Principal Component (\%) }\end{array}$ \\
\hline Existing & 1 & 1.1378 & 0.879 & Tran-Y & 49.52 \\
Existing & 2 & 1.3515 & 0.740 & Rot-Z & 54.77 \\
Existing & 3 & 1.5830 & 0.632 & Tran-X & 70.79 \\
\hline Retrofitted & 1 & 3.603 & 0.278 & Tran-Y & 75.70 \\
Retrofitted & 2 & 3.963 & 0.252 & Tran-X & 77.52 \\
Retrofitted & 3 & 5.001 & 0.200 & Rot-Z & 91.93 \\
\hline
\end{tabular}

The increase in the overall stiffness of the structure leads to a lower fundamental vibration period, which belongs to the range that defines the response spectrum plateau and is thus associated with the maximum spectral acceleration, as shown in Figure 17. This fact, together with the mass increment due to the new ICF exoskeleton (approximatively $10 \%$ that of the original building), led to an increased global seismic force on the retrofitted structure, for which the exoskeleton was designed.

However, the increased stiffness of the retrofitted structure also led to a strong reduction of the structural displacements and inter-story drifts: at the life safety seismic ultimate limit state (SLV) [51], the top displacement reduced from $17.15 \mathrm{~cm}$ (in the original state) to $2.62 \mathrm{~cm}$ (in the retrofitted situation), consisting of an $85 \%$ reduction. This corresponded to a proportional reduction of the overall seismic demand on existing structures, which was seismically retrofitted with the proposed intervention. 


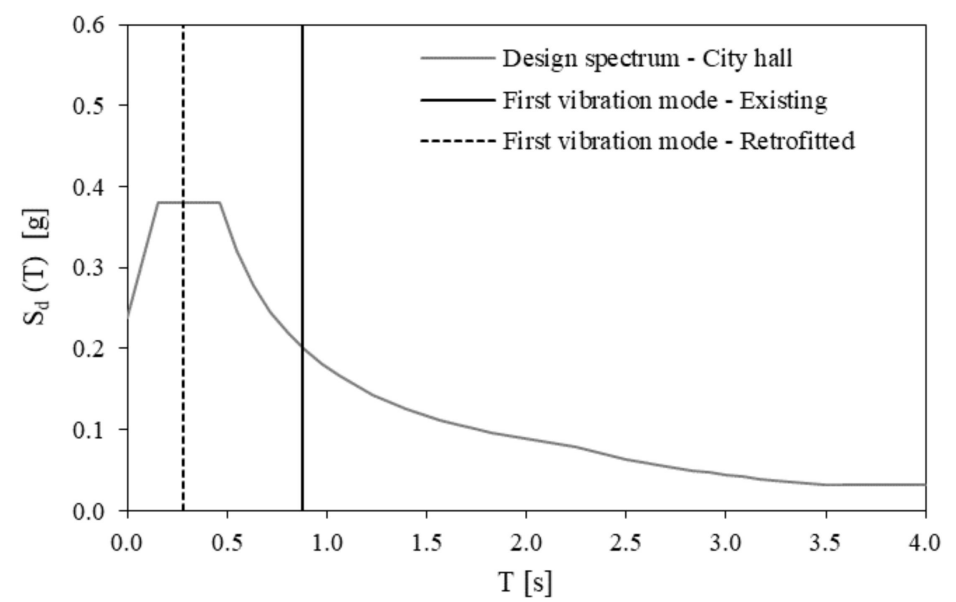

Figure 17. Design response spectrum and fundamental vibration periods for the city Hall building. Design spectrum was calculated according to the Italian standard NTC18 [51] for life safety seismic ultimate limit state (SLV), using a return period of 75 years.

\subsection{Case Study: Educational Facility}

The analyzed case study is an educational facility located in Basiliano (Italy) with an RC frame structure. The building is represented in Figure 18, and it is composed of two portions, named "block 1" and "block 2", which were built in 1971 and 1979, respectively.

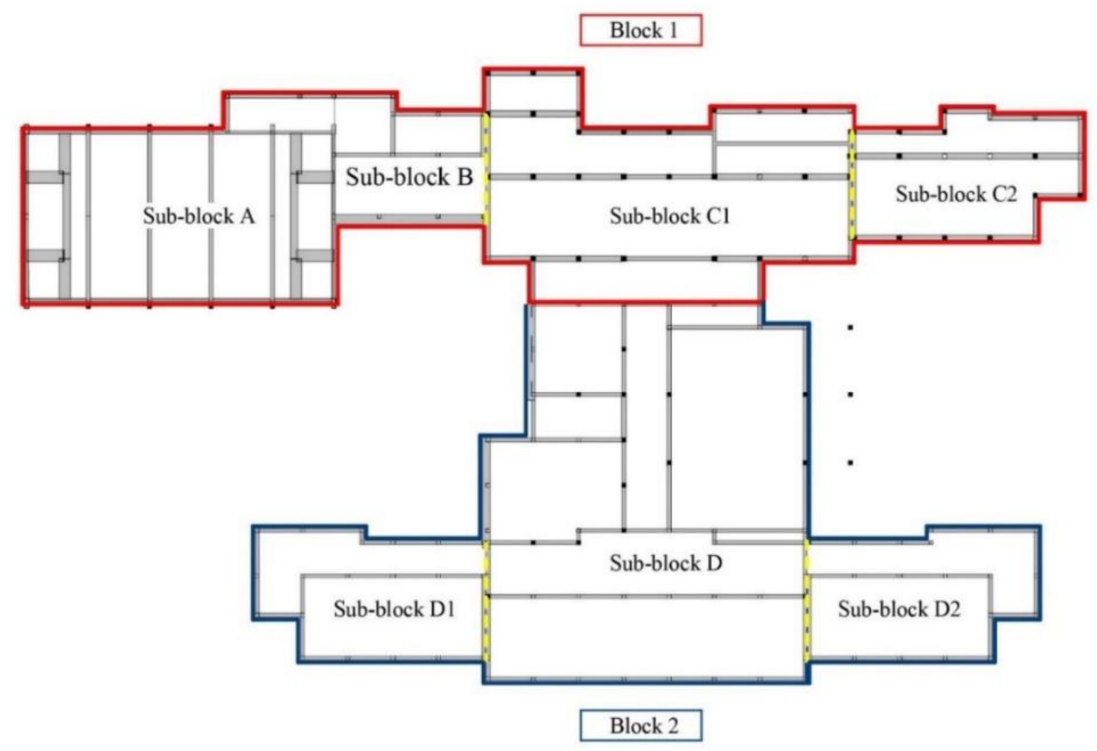

Figure 18. Educational facility building: Definition of the parts with different age of construction (adapted and modified from Pertile et al. [49]).

Block 1 consists of the classrooms and teacher offices that are connected by a service area with locker rooms to the gym. Block 2 consists of additional classrooms, the auditorium, and the music laboratory. The two blocks are composed of four and three sub-blocks, respectively, separated by construction joints.

Block 1 was designed according to pre-1970s practice when capacity design and seismic detailing were not yet introduced. The structural system consists of RC frames aligned only in the longitudinal direction; in the transversal direction, there are no structures that can resist horizontal loads. Sub-block A has one story with a total height of $7.3 \mathrm{~m}$; sub-block $\mathrm{B}$ is one-story with a total height of $3.8 \mathrm{~m}$; sub-blocks $\mathrm{C} 1$ and $\mathrm{C} 2$ have two stories above ground and one story partially underground, with a total height of $9.5 \mathrm{~m}$ above ground. 
Block 2 was built after the first Italian seismic regulation [54] ("Legge n. 64 del 2 Febbraio 1974"), with the first specifications about seismic detailing. Being more recent, it presents an improved structural system that consists of RC frames with better characteristics of materials and a higher geometric reinforcement ratio. Block 2 is composed of one story with a medium height of $4.5 \mathrm{~m}$. Sub-block D frames had double beams due to flat roofs at different heights connected to the same frame.

The original project was studied, and on-site tests were performed. The on-site structural diagnostic campaign confirmed the structural details in the original drawings. Some non-destructive and partially destructive tests were performed to assess the mechanical parameters of the materials employed in the construction. Tests with hammer and crushing tests of hardened concrete core samples returned the compressive strength of the concrete; tests with a cover meter confirmed the presence of the rebars indicated in the drawings, and tensile tests on bars extracted from columns gave the tensile strength of the reinforcing steel. Table 5 lists the values assumed for the existing material properties.

Table 5. Material characteristics of existing structures.

\begin{tabular}{ccccccc}
\hline Material & Class & Type & $\mathbf{f}_{\mathbf{m}} \mathbf{( M P a )}$ & $\mathbf{E}(\mathbf{G P a})$ & $\gamma_{\mathbf{M}}$ & FC \\
\hline Concrete & Rck300 & Existing & 28.6 & 30 & 1.5 & 1.2 \\
Steel & Aq50 & Existing & 270 & 210 & 1.15 & 1.2 \\
\hline
\end{tabular}

The typical section of the columns is $30 \times 35 \mathrm{~cm}$ at the basement and $30 \times 30 \mathrm{~cm}$ at the upper levels. All the columns are continuous from the foundation to the roof. The section of the beams is $50 \times 23 \mathrm{~cm}$ for the internal frame and $40 \times 23 \mathrm{~cm}$ for the external frames. Geometry and reinforcement details of columns and beams are shown in Figure 19. The $\mathrm{RC}$ and hollow tiles mixed floors have $200+30 \mathrm{~mm}$ thickness, with a total thickness equal to the height of the beams.
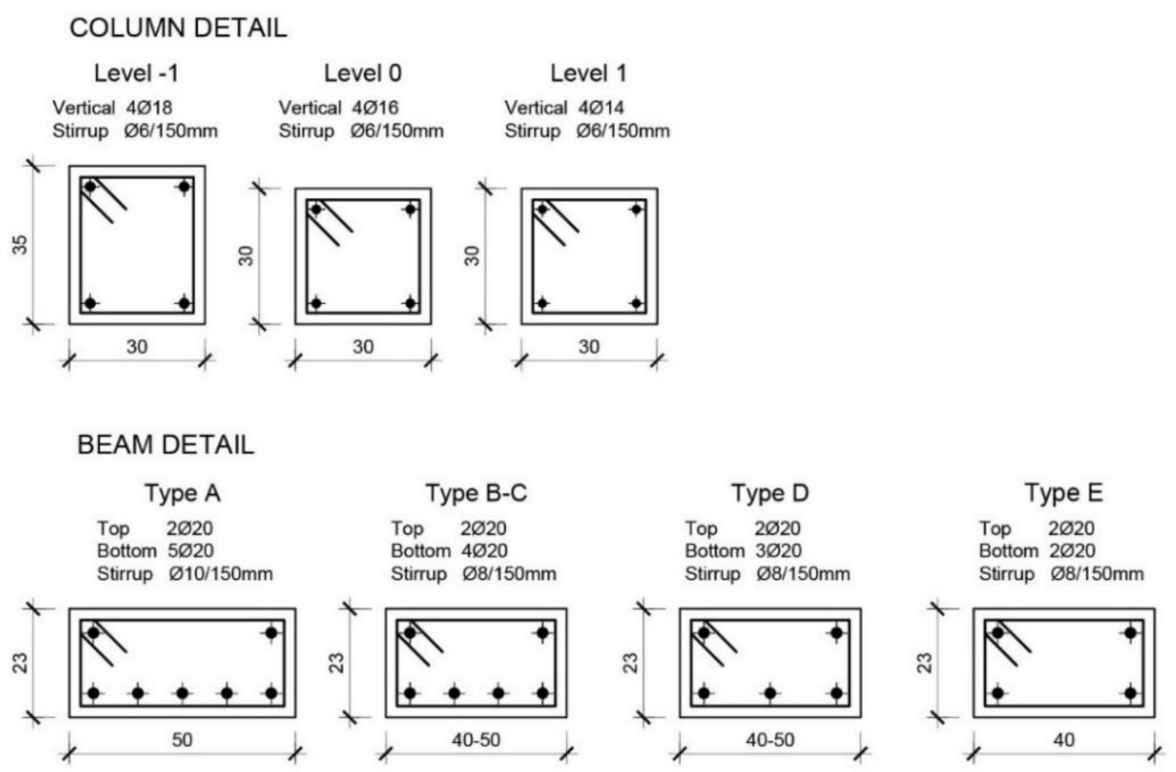

Figure 19. Cross-section of existing members for sub-blocks $C 1$ and $C 2$ (adapted and modified from Pertile et al. [49]).

Vulnerability assessment of the existing structures showed poor seismic performance, highlighting the need for a strengthening intervention. The retrofitting of Block 2 was performed with traditional steel braces technology to reduce the displacement demand on existing frame structures. Details of this intervention are not discussed in this work. In Block 1, for sub-blocks A, C1, and C2, the ICF retrofitting technology presented in this 
work was applied. For the sake of brevity, in the following, only the design for sub-blocks $\mathrm{C} 1$ and $\mathrm{C} 2$ is reported.

The construction joint between Sub-blocks $\mathrm{C} 1$ and $\mathrm{C} 2$ has been seamed by the new exoskeleton applied on the outer of the building and cross-stitching with tie bars epoxied into holes at $45^{\circ}$ at floor level. In the retrofitted configuration, Sub-blocks $\mathrm{C} 1$ and $\mathrm{C} 2$ have been considered as a unique structure, with plan dimensions of $49 \times 13 \mathrm{~m}$. The inter-story height of the underground level is $3.3 \mathrm{~m}$, and for the ground and first levels it is $3.8 \mathrm{~m}$. As mentioned before, the existing building structural system consisted of reinforced concrete frames parallel to the longitudinal direction, with $3.75 \mathrm{~m}$ spans. The new earthquakeresistant exoskeleton built outside the building is continuous from the foundation level to the roof and is connected to the edge beams of each story and to the external columns. The RC layer of the ICF system is $150 \mathrm{~mm}$ thick, and rebars are placed on two layers.

In addition to the application of the retrofit system on the outer facades, the elongated plan shape of the building required the addition of two internal RC walls evidenced with green outlines in Figure 20b to resist the seismic load in the weakest direction (i.e., transverse direction). For the new structural walls, concrete of class C25/30 and steel of class B450C were used, according to the Italian standard NTC18 [51]. The materials mechanical properties are reported in Table 6 .

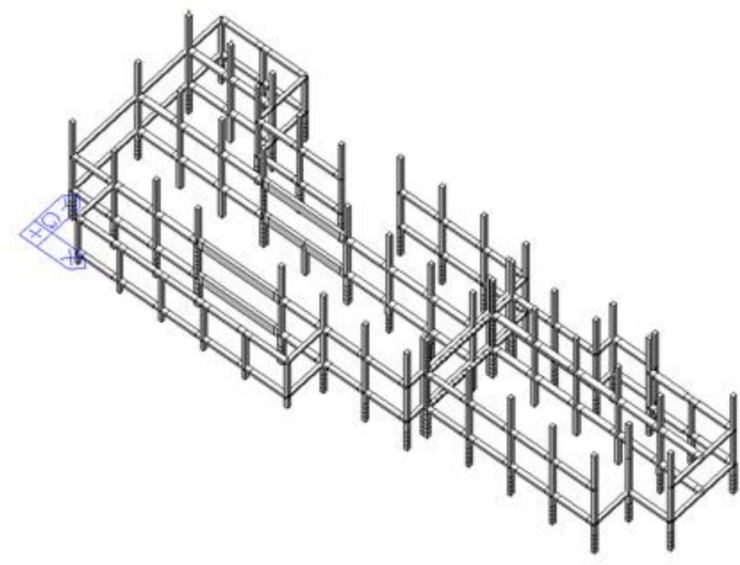

(a)

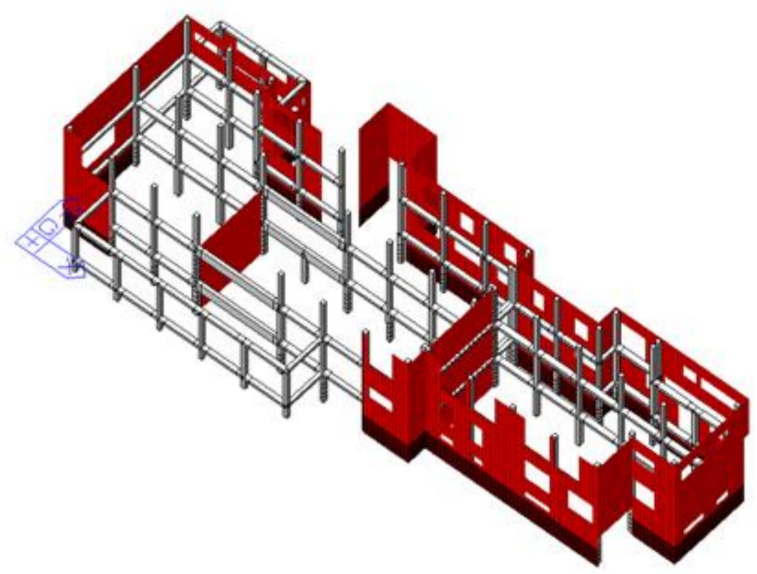

(b)

Figure 20. Numerical model of block $\mathrm{C} 1+\mathrm{C} 2$ : (a) existing structure; (b) retrofitted structure (adapted and modified from Pertile et al. [49]).

Table 6. Material characteristics of retrofitting system.

\begin{tabular}{ccccccc}
\hline Material & Class & Type & $\mathbf{f}_{\mathbf{k}}(\mathbf{M P a})$ & $\mathbf{E}(\mathrm{GPa})$ & $\gamma_{\mathbf{M}}$ & FC \\
\hline Concrete & C25/30 & New & 25 & 30 & 1.5 & 1 \\
Steel & B450C & New & 450 & 210 & 1.15 & 1 \\
\hline
\end{tabular}

A finite element model of the structure was built using the commercial code Midas Gen [53]. The aim of the numerical analysis was first to assess the vulnerability of the actual state of the structure and then to design the seismic retrofitting of the building. Models of the existing and retrofitted structure are illustrated in Figure 20.

The existing RC frames were modeled with beam elements that had the geometry and materials specified in the previous section. The ICF concrete layer was modeled with plate elements with the actual thickness and the aforementioned material properties. The infill and the partition walls were not modeled but were taken into account only in terms of mass. The new earthquake-resistant structure and the RC frame structure were linked to vertical and horizontal truss elements, as already illustrated in the presentation of the previous case study. The truss elements were used to design the dimension and 
the spacing of connections needed to transfer loads from the existing structure to the retrofitting membrane.

Gravity loads are defined according to the floor use, following Italian provisions about loading conditions as reported in standard NTC18 [51]. The finite element model was conceived to assign the vertical static loads to the existing structure, while the ICF concrete layers were vertically loaded only with their self-weight.

A modal response spectrum analysis was performed for the existing structure, using the acceleration response spectrum shown in Figure 21. The low thickness of the concrete layer of the existing floors does not fulfill the requirements for the assumption of the rigid diaphragm according to the Italian standard NTC18 [51]: the flexible floor causes amplification of stresses in the peripheric columns. The gap of the construction joint between sub-bodies $\mathrm{C} 1$ and $\mathrm{C} 2$ proved to be not sufficient to prevent pounding effects.

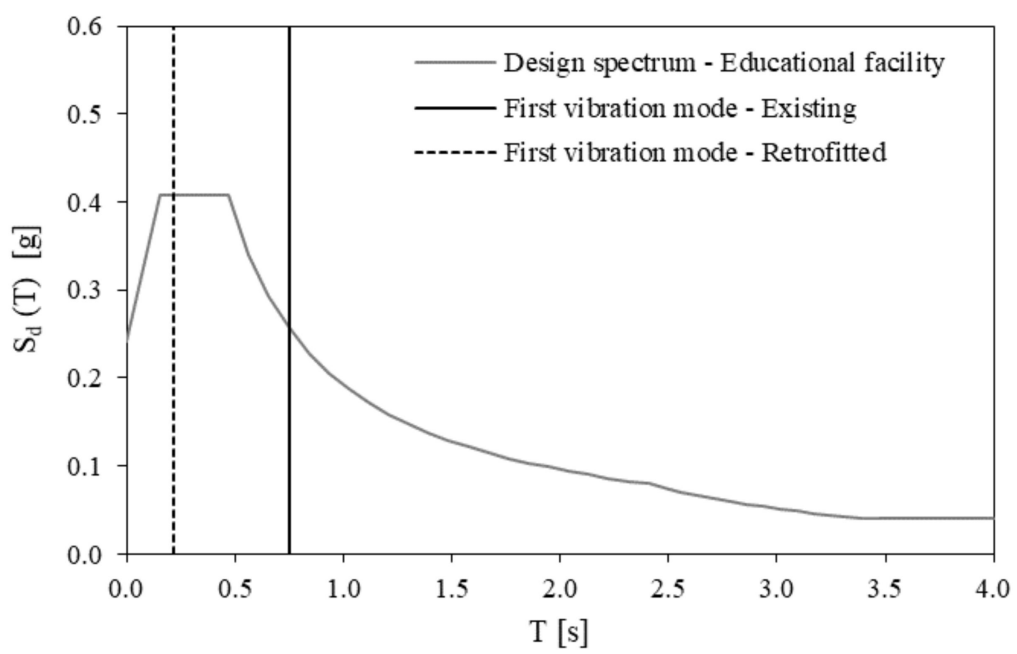

Figure 21. Design response spectrum and fundamental vibration periods for the educational facility case-study building. Design spectrum was calculated according to the Italian standard NTC18 [51] for life safety seismic ultimate limit state (SLV), using a return period of 75 years.

The same analysis was performed on the retrofitted structure, which has a higher stiffness with respect to the $\mathrm{RC}$ frames. As a consequence, the main vibration periods of the building decrease, as shown in Table 7, and the seismic action increases, as shown in Figure 21.

Table 7. Modal analysis results for educational facility.

\begin{tabular}{cccccc}
\hline Model & Mode & $\begin{array}{c}\text { Principal } \\
\text { Direction }\end{array}$ & $\begin{array}{c}\text { Frequency } \\
\mathbf{( H z )}\end{array}$ & Period (s) & $\begin{array}{c}\text { Mass Ratio } \\
\mathbf{( \% )}\end{array}$ \\
\hline Existing & 1 & Tran-Y & 1.338 & 0.748 & 71.65 \\
Existing & 2 & Rot-Z & 1.558 & 0.642 & 55.26 \\
Existing & 3 & Tran-X & 1.768 & 0.566 & 53.72 \\
\hline Retrofitted & 1 & Tran-Y & 4.624 & 0.216 & 81.27 \\
Retrofitted & 2 & Tran-X & 7.434 & 0.135 & 74.70 \\
Retrofitted & 3 & Rot-Z & 8.427 & 0.119 & 80.04 \\
\hline
\end{tabular}

After the retrofit, the stresses in elements of the existing RC frames have been drastically reduced, since the majority of the seismic load is carried by the new concrete membrane due to its prevailing lateral stiffness. The increment of the seismic load is compensated by the higher strength of the new structure, designed according to the current design specifications of the Italian standard NTC18 [51]. A positive effect of the global stiffening of the structure is the decrease in total displacements and inter-story drifts, with the consequent decrease in the deformation demand on members of the existing structure. 


\subsection{Conclusions}

European building stock is characterized by elevated seismic vulnerability and energy consumption. Most buildings present serious structural deficiencies against seismic action and high energy demand for heating and cooling caused by poor insulation of the building envelope, usually coupled with elevated greenhouse gasses emissions. There is a large need for integrated retrofitting solutions that can improve both structural and energy performances of existing buildings.

In this work, an innovative integrated retrofitting technology based on insulated concrete formwork panels has been presented. The proposed technology is conceived to provide structural strengthening and thermal insulation, together with an architectural refurbishment. The proposed technology has been described in detail, analyzing single components and installation phases. Since the retrofitting intervention is conceived to be applied outside the buildings, it avoids interruptions of inside activities. Moreover, the formworks are prefabricated ad hoc to facilitate and speed up the installation phases on site.

Insights into the design of structural components have been provided, and a calculation example has been reported for a simple case study masonry building, for which experimental results of a cyclic loading test were available. The cyclic behavior and failure mode of the building have been discussed. Moreover, procedures for analytical strength calculations have been reported, based on the approaches provided by Italian standard NTC18 [51] and Eurocode 2 [52]. Analytical evaluations of the horizontal global strength were performed using both design values and mean experimental values of material strengths, comparing the results of the latter case with those obtained experimentally. The comparison demonstrated that the adopted calculation approach is conservative and can be safely employed in design practice.

Moreover, possible procedures for the structural modeling of buildings retrofitted with the proposed system have been illustrated. Two case studies are reported to describe how to model and analyze the retrofit interventions performed on complex RC frame and masonry buildings, also characterized by strong plan irregularity.

Numerical analyses showed that retrofitted buildings present increased lateral stiffness, which translates in lower vibration periods, often belonging to the plateau of seismic response spectra. However, this increase in seismic demand is also accompanied by a much more significant increment of lateral load-carrying capacity. The increased stiffness of the retrofitted buildings allows a marked reduction in deformation demand of existing structural members at the considered seismic ultimate limit state and a limitation of drift-induced damages to non-structural elements for low-to-medium intensity earthquakes.

Author Contributions: Conceptualization, V.P., A.S., L.D.S. and R.S.; methodology and formal analysis, V.P. and A.S.; visualization, V.P. and A.S.; writing—original draft preparation, V.P. and A.S.; writing - review and editing, A.S., L.D.S. and R.S.; supervision, L.D.S. and R.S.; project administration, R.S.; funding acquisition, R.S. All authors have read and agreed to the published version of the manuscript.

Funding: Research presented was funded by POR-FSE Veneto 2014-2020, project No. 2105-54-21212015.

Informed Consent Statement: Not applicable.

Data Availability Statement: All the resulting data are reported in the present article.

Acknowledgments: The authors would like to thank the company Ecosism S.r.l. (https:/ /www. ecosism.com accessed on 30 April 2021) for the economic and technical support provided in the performing of the experimental tests.

Conflicts of Interest: The authors declare no conflict of interest. 


\section{References}

1. Palermo, V.; Tsionis, G.; Sousa, M.L. Building Stock Inventory to Assess Seismic Vulnerability across Europe; Publication office of the European Union: Luxembourg, 2018; ISBN 9789279867071.

2. JCR Joint Research Center Best Environmental Management Practice for the Building and Construction Sector. Sect. Ref. Doc. Best Environ. Manag. Pract. EMAS; Joint Research Center (JRC): Seville, Spain, 2012; p. 611.

3. Marini, A.; Passoni, C.; Riva, P.; Negro, P.; Romano, E.; Taucer, F. Technology Options for Earthquake Resistant, Eco-Efficient Buildings in Europe: Research Needs; Publications Office of the European Union: Luxembourg, 2014; ISBN 9789279354243.

4. Casprini, E.; Passoni, C.; Belleri, A.; Marini, A.; Bartoli, G.; Riva, P. Demolition-and-Reconstruction or Renovation? Towards a Protocol for the Assessment of the Residual Life of Existing RC Buildings. IOP Conf. Ser. Earth Environ. Sci. 2019, $290,012010$. [CrossRef]

5. Hasik, V.; Escott, E.; Bates, R.; Carlisle, S.; Faircloth, B.; Bilec, M.M. Comparative whole-building life cycle assessment of renovation and new construction. Build. Environ. 2019, 161, 106218. [CrossRef]

6. Calvi, G.M.; Sousa, L.; Ruggeri, C. Energy Efficiency and Seismic Resilience: A Common Approach. In Multi-Hazard Approaches to Civil Infrastructure Engineering; Springer: Berlin, Germany, 2016; pp. 165-208, ISBN 9783319297132.

7. Belleri, A.; Marini, A. Does seismic risk affect the environmental impact of existing buildings? Energy Build. 2016, 110, 149-158. [CrossRef]

8. Pohoryles, D.A.; Maduta, C.; Bournas, D.A.; Kouris, L.A. Energy Performance of Existing Residential Buildings in Europe: A Novel Approach Combining Energy with Seismic Retrofitting. Energy Build. 2020, 223, 110024. [CrossRef]

9. Mastroberti, M.; Bournas, D.; Vona, M.; Manganelli, B.; Palermo, V. Combined Seismic Plus Energy Retrofitting for the Existing Rc Buildings: Economic Feasibility. In Proceedings of the 16th European Conference on Earthquake Engineering, Thessaloniki, Greece, 18-21 June 2018.

10. Marini, A.; Passoni, C.; Belleri, A.; Feroldi, F.; Preti, M.; Metelli, G.; Riva, P.; Giuriani, E.; Plizzari, G. Combining seismic retrofit with energy refurbishment for the sustainable renovation of RC buildings: A proof of concept. Eur. J. Environ. Civ. Eng. 2017, 1-21. [CrossRef]

11. Zanni, J.; Labò, S.; Passoni, C.; Casprini, E.; Marini, A.; Belleri, A.; Menna, C. Incremental Integrated Holistic Rehabilitation: A New Concept to Boost a Deep Renovation of the Existing Building Stock. IOP Conf. Ser. Earth Environ. Sci. 2019, $290,012140$. [CrossRef]

12. Passoni, C.; Marini, A.; Belleri, A.; Menna, C. Redefining the concept of sustainable renovation of buildings: State of the art and an LCT-based design framework. Sustain. Cities Soc. 2021, 64, 102519. [CrossRef]

13. La Greca, P.; Margani, G. Seismic and energy renovation measures for sustainable cities: A critical analysis of the Italian scenario. Sustainability 2018, 10, 254. [CrossRef]

14. Berardi, U. A cross-country comparison of the building energy consumptions and their trends. Resour. Conserv. Recycl. 2017, 123, 230-241. [CrossRef]

15. Bournas, D. Innovative Materials for Seismic and Energy Retrofitting of the Existing EU Buildings; Publications Office of the European Union: Luxembourg, 2018; ISBN 9789279819957.

16. Zhang, Y.; Yan, D.; Hu, S.; Guo, S. Modelling of energy consumption and carbon emission from the building construction sector in China, a process-based LCA approach. Energy Policy 2019, 134, 110949. [CrossRef]

17. Sadineni, S.B.; Madala, S.; Boehm, R.F. Passive building energy savings: A review of building envelope components. Renew. Sustain. Energy Rev. 2011, 15, 3617-3631. [CrossRef]

18. De Felice, G.; Giannini, R. Out-of-plane seismic resistance of masonry walls. J. Earthq. Eng. 2001, 5, 253-271. [CrossRef]

19. Simsir, C.C.; Aschheim, M.A.; Abrams, D.P. Out-of-plane dynamic response of unreinforced bearing walls attached to flexible diaphragms. In Proceedings of the 13th World Conference on Earthquake Engineering, Vancouver, BC, Canada, 1-6 August 2004; Volume 15, pp. 1-6.

20. Ferreira, T.M.; Costa, A.A.; Costa, A. Analysis of the Out-Of-Plane Seismic Behavior of Unreinforced Masonry: A Literature Review. Int. J. Archit. Herit. 2015, 9, 949-972. [CrossRef]

21. Abrams, D.P.; AlShawa, O.; Lourenço, P.B.; Sorrentino, L. Out-of-Plane Seismic Response of Unreinforced Masonry Walls: Conceptual Discussion, Research Needs, and Modeling Issues. Int. J. Archit. Herit. 2017, 11, 22-30. [CrossRef]

22. Giuffrè, A. Sicurezza E Conservazione Dei Centri Storici-Il Caso Ortigia (In Italian); Editori Laterza: Laterza, Italy, 1993.

23. Paulay, T.; Priestley, M.J.N. Seismic Design of Reinforced Concrete and Masonry Buildings; John Wiley \& Sons, Inc.: Hoboken, NJ, USA, 1992; ISBN 9780470172841.

24. Magenes, G.; Calvi, G.M. In-plane seismic response of brick masonry walls. Earthq. Eng. Struct. Dyn. 1997, $26,1091-1112$. [CrossRef]

25. Calderini, C.; Cattari, S.; Lagomarsino, S. In-plane strength of unreinforced masonry piers. Earthq. Eng. Struct. Dyn. 2009, 39, 243-267. [CrossRef]

26. Penazzi, D.; Valluzzi, M.R.; Saisi, A.; Binda, L.; Modena, C. Repair and strengthening of historic masonry buildings in seismic areas. In Proceedings of the International Millennium Congress "More than two thousand years in the history of Architecture, Safeguarding the structures of our architectural heritage", Paris, France, 10-12 December 2001; Volume 2, pp. 1-7. 
27. Modena, C.; Casarin, F.; Porto, F.; Garbin, E.; Mazzon, N.; Munari, M.; Panizza, M.; Valluzzi, M.R. Structural interventions on historical masonry buildings: Review of Eurocode 8 provisions in the light of the Italian experience. In Proceedings of the Eurocode 8 Perspectives from the Italian Standpoint Workshop, Naples, Italy; Cosenza, E., Ed.; pp. 225-236. Available online: https:/ / cupdf.com/document/claudio-modena-filippo-casarin-francesca-da-porto-claudio-modena-filippo.html (accessed on 1 March 2021).

28. Churilov, S.; Dumova-Jovanoska, E. Analysis of masonry walls strengthened with RC jackets. In Proceedings of the 15th WCEE, Lisbon, Portugal, 24-28 September 2012.

29. Masi, A.; Santarsiero, G.; Chiauzzi, L.; Gallipoli, M.R.; Piscitelli, S.; Vignola, L.; Bellanova, J.; Calamita, G.; Perrone, A.; Lizza, C.; et al. Different damage observed in the villages of Pescara del Tronto and Vezzano after the M6.0 august 24, 2016 central Italy earthquake and site effects analysis. Ann. Geophys. 2016, 59, 1-12. [CrossRef]

30. Scotta, R.; Trutalli, D.; Marchi, L.; Pozza, L. Seismic performance of URM buildings with in-plane non-stiffened and stiffened timber floors. Eng. Struct. 2018, 167, 683-694. [CrossRef]

31. Gubana, A.; Melotto, M. Cyclic numerical analyses on wood-based in-plane retrofit solutions for existing timber floors. Structures 2021, 33, 1764-1774. [CrossRef]

32. ICC (International Code Council). International Building Code; International Code Council Inc.: Country Club Hills, IL, USA, 2018; Volume 51, ISBN 9788578110796.

33. Ricci, P.; de Luca, F.; Verderame, G.M. 6th April 2009 L'Aquila earthquake, Italy: Reinforced concrete building performance. Bull. Earthq. Eng. 2011, 9, 285-305. [CrossRef]

34. Priestley, M.J.N.; Calvi, G.M.; Kowalsky, M.J. Displacement Based Seismic Design of Structures; IUSS Press: Pavia, Italy, 2007.

35. Mazza, F.; Donnici, A. In-Plane and Out-of-Plane Seismic Damage of Masonry Infills in Existing R.c. Structures: The case Study of De Gasperi-Battaglia School in Norcia; Springer: Dordrecht, The Netherlands, 2021; Volume 19, ISBN 0123456789.

36. Verderame, G.M.; Iervolino, I.; Ricci, P. Report on the Damages on Buildings Following the Seismic Event of 6th of April 2009, V1.10. Available online: http:/www.reluis.it (accessed on 30 April 2021).

37. Tsionis, G.; Apostolska, R.; Taucer, F. Seismic Strengthening of RC Buildings, JRC Science and Policy Reports; Publications Office of the European Union: Rome, Italy, 2014.

38. Takeuchi, T.; Yasuda, K.; Iwata, M. Seismic retrofitting using energy dissipation Façades. In Proceedings of the Improving the Seismic Performance of Existing Buildings and Other Structures-Proc. 2009 ATC and SEI Conference on Improving the Seismic Performance of Existing Buildings and Other Structures, San Francisco, CA, USA, 9-11 December 2009; Volume 41084, pp. 1000-1009.

39. Feroldi, F.; Marini, A.; Plizzari, G.A.; Giuriani, E.; Riva, P.; Belleri, A. Energy efficiency upgrading, architectural restyling and structural retrofit of modern buildings by means of "engineered" double skin façade. Struct. Archit. 2013, 1859-1866. [CrossRef]

40. Labò, S.; Passoni, C.; Marini, A.; Belleri, A.; Camata, G.; Riva, P.; Spacone, E. Diagrid solutions for a sustainable seismic, energy, and architectural upgrade of European RC buildings. In Proceedings of the XII International Conference on Structural Repair and Rehabilitation CINPAR, Bergamo, Italy, 26-29 October 2016.

41. Labò, S.; Passoni, C.; Marini, A.; Belleri, A.; Camata, G.; Riva, P.; Spacone, E. Prefabricated responsive diagrids for holistic renovation of existing MID-RISE RC buildings. In Proceedings of the COMPDYN 2017-Proceedings of the 6th International Conference on Computational Methods in Structural Dynamics and Earthquake Engineering, Rhodes Island, Greece, 15-17 June 2017; Volume 2, pp. 4234-4244.

42. Reggio, A.; Restuccia, L.; Martelli, L.; Ferro, G.A. Seismic performance of exoskeleton structures. Eng. Struct. 2019, 198, 109459. [CrossRef]

43. Labò, S.; Passoni, C.; Marini, A.; Belleri, A. Design of diagrid exoskeletons for the retrofit of existing RC buildings. Eng. Struct. 2020, 220, 110899. [CrossRef]

44. Passoni, C.; Guo, J.; Christopoulos, C.; Marini, A.; Riva, P. Design of dissipative and elastic high-strength exoskeleton solutions for sustainable seismic upgrades of existing RC buildings. Eng. Struct. 2020, 221, 111057. [CrossRef]

45. Manfredi, V.; Masi, A. Seismic strengthening and energy efficiency: Towards an integrated approach for the rehabilitation of existing RC buildings. Buildings 2018, 8, 36. [CrossRef]

46. Bournas, D.A. Concurrent seismic and energy retrofitting of RC and masonry building envelopes using inorganic textile-based composites combined with insulation materials: A new concept. Compos. Part B Eng. 2018, 148, 166-179. [CrossRef]

47. Marini, A.; Belleri, A.; Feroldi, F.; Passoni, C.; Preti, M.; Riva, P.; Giuriani, E.; Plizzari, G. Coupling energy refurbishment with structural strengthening in retrofit interventions. In Proceedings of the SAFESUST Workshop, Ispra, Italy, 26-27 November 2015; Caverzan, A., Lamperti Tornaghi, M., Nigro, P., Eds.;

48. CEN EN 1998-1 Eurocode 8: Design of structures for earthquake resistance-Part 1: General rules, seismic actions and rules for buildings. Eur. Comm. Norm. Brussels 2004. [Authority: The European Union per Regulation 305/2011, Directive 98/34/EC, Directive 2004/18/EC].

49. Pertile, V.; Stella, A.; De Stefani, L.; Scotta, R. Seismic and energy integrated retrofitting of existing buildings: Two case studies in italy. In Proceedings of the WCEE 2020-17th World Conference on Earthquake Engineering, Sendai, Japan, 27 September-2 October 2020.

50. Trutalli, D.; Marchi, L.; Scotta, R.; Pozza, L. Seismic capacity of irregular unreinforced masonry buildings with timber floors. Proc. Inst. Civ. Eng.Struct. Build. 2021, 174, 473-490. [CrossRef] 
51. Ministero delle Infrastrutture e dei Trasporti. DM 17/01/2018 Aggiornamento delle «Norme tecniche per le costruzioni». Gazz. Uff. Della Repubb. Ital. 2018.

52. CEN EN 1992-1-1 Eurocode 2: Design of concrete structures-Part 1-1: General rules and rules for buildings. Eur. Comm. Norm. Brussels 2014.

53. Midasoft Midas GEN. Available online: https://www.midasoft.com/building/products/midasgen (accessed on 30 April 2021).

54. Dei Lavori Pubblici M. Legge ${ }^{\circ} 64$ del 2 febbraio 1974-Provvedimenti per le costruzioni con particolari prescrizioni per le zone sismiche. Gazz. Uff. della Repubb. Ital. 1974. 